Discussion

Papers

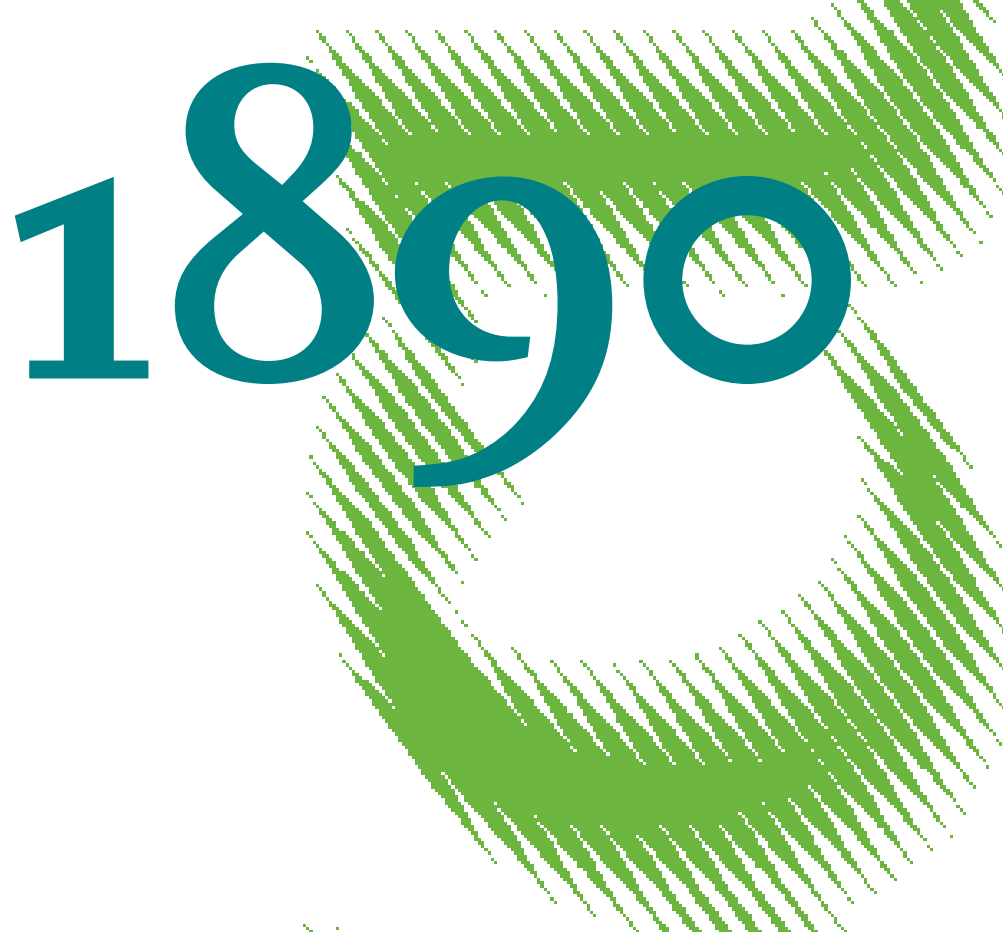

\title{
Airbnb and Rents: Evidence from Berlin
}


Opinions expressed in this paper are those of the author(s) and do not necessarily reflect views of the institute.

IMPRESSUM

(C) DIW Berlin, 2020

DIW Berlin

German Institute for Economic Research

Mohrenstr. 58

10117 Berlin

Tel. +49 (30) $89789-0$

Fax +49 (30) $89789-200$

http://www.diw.de

ISSN electronic edition 1619-4535

Papers can be downloaded free of charge from the DIW Berlin website:

http://www.diw.de/discussionpapers

Discussion Papers of DIW Berlin are indexed in RePEc and SSRN:

http://ideas.repec.org/s/diw/diwwpp.html

http://www.ssrn.com/link/DIW-Berlin-German-Inst-Econ-Res.html 


\title{
Airbnb and Rents: Evidence from Berlin
}

\author{
Tomaso Duso, Claus Michelsen, Maximilian Schäfer, and Kevin Ducbao Tran ${ }^{1}$
}

August 13, 2020

\begin{abstract}
Cities worldwide have regulated peer-to-peer short-term rental platforms claiming that those platforms remove apartments from the long-term housing market, causing an increase in rents. Establishing and quantifying such a causal link is, however, challenging. We investigate two policy changes in Berlin to first assess how effective they were in regulating Airbnb, the largest online peer-to-peer short-term rental platform. We document that the policy changes reduced the number of entire homes listed on Airbnb substantially, by eight to ten listings per square kilometer. In particular the introduction of limitations on the misuse of regular rental apartments as short-term accommodations, also strongly reduced the average number of days per year that Airbnb listings are available for booking. In a second step, we then use this policy-induced change in Airbnb supply to assess the impact of Airbnb on rents in the city. Our results suggest that each nearby apartment on Airbnb increases average monthly rents by at least seven cents per square meter. This effect is larger for Airbnb listings that are available for rent for a larger part of the year. Further analyses suggest some effect heterogeneity across the city. In particular, areas with lower Airbnb density tend to be affected more by additional Airbnb listings.
\end{abstract}

Keywords: rents, housing market, short-term rental regulation, sharing economy, Airbnb

JEL codes: R21, R31, R52, Z30

\footnotetext{
${ }^{1}$ Duso is head of the Firms and Markets department at the German Institute for Economic Research (DIW Berlin), professor of empirical industrial economics at Technische Universität Berlin (TU Berlin), and Research Fellow at CEPR and CESifo. Email: tduso@diw.de. Michelsen is head of the Forecasting and Economic Policy department at the DIW Berlin and lecturer at Universität Potsdam. Email: cmichelsen@diw.de. Schäfer is a Ph.D. candidate in economics at the Berlin School of Economics, DIW Berlin, and TU Berlin. E-mail: mschaefer@diw.de. Tran is a Ph.D. candidate in economics at the Berlin School of Economics, DIW Berlin, and TU Berlin. E-mail: ktran@diw.de

We thank Empirica for granting us access to rent data. We thank participants at Católica Lisbon, DIW Berlin, EARIE 2019, Hertie School of Governance, Télécom Paris, and the University of Mannheim for helpful comments. We thank Adam Lederer for editorial support. All remaining errors are our own.
} 


\section{Introduction}

Cities worldwide are regulating online short-term rental platforms, such as Airbnb. One rationale behind these regulations is that short-term renting removes apartments from the long-term rental market, thereby contributing to rising rents. Documenting and quantifying such a causal relationship is, however, challenging. Understanding the effectiveness of short-term rental regulation and whether it actually affects rents is important for assessing these regulations ex-post and to guide policy-making with regard to online short-term rental platforms in the future.

In this paper, we address two main issues: First, we assess whether policy changes induced by short-term rental regulation in Berlin (the so-called ZweckentfremdungsverbotGesetz (ZwVbG)) affected the supply of apartments on Airbnb, the largest online short-term rental platform. Second, we use the plausibly exogenous variation in Airbnb listings due to the policy changes to analyze the causal link between Airbnb and rents. Furthermore, we shed light on the heterogeneity of the effect with regard both to the geography as well as to characteristics of Airbnb listings and rental apartments.

Our paper contributes to a small, but growing, literature on the causal impact of Airbnb on the housing market. Common approaches to address the inherent endogeneity in establishing this causal link are controlling directly for omitted variables bias and reverse causality (Horn and Merante, 2017), using shift-share-like instruments for Airbnb popularity (Barron et al., 2020, Garcia-López et al., 2019), and using policy changes as natural experiments (Koster et al. 2018). We contribute new evidence based on two policy changes in Berlin and by using instrumental variables (IV) methods to establish causality. In addition to our natural experiment setting, we use a wide range of potential covariates in an attempt to exclude omitted variable bias to the fullest possible extent. To deal with this large number of covariates, we use the Lasso-based regression methods proposed by Belloni et al. (2014) and Chernozhukov et al. (2015) for model selection. The broad set of observable characteristics on rentals and Airbnb listings also allows us to explore the heterogeneity of the effect of Airbnb on rents in more detail. So far, the literature mostly focuses on average effects.

Most of the literature analyzes the topic for different regions in the US (Horn and Merante, 2017; Koster et al., 2018, Barron et al., 2020, Valentin, 2020). Evidence for Europe is scarcer with Garcia-López et al. (2019) analyzing the case of Barcelona. Thus, we add empirical evidence for the European context by studying Airbnb in Berlin which, as of early 2019, had 
the fifth-largest number of Airbnb listings among European cities $2^{2}$

In our analysis, we first document that the two policy reforms aimed at curbing shortterm accommodations in the city decreased the average number of entire homes listed on Airbnb by eight to ten listings per square kilometer. We further show that in particular the first policy reform which essentially restricted the misuse of regular apartments as short-term rental accommodations, also strongly decreased the average number of days per year that Airbnb listings are available for booking. Using these policy-induced changes to Airbnb in the city, in a second step, we find that each additional nearby entire home on Airbnb increases monthly rents by at least seven cents per square meter. However, we show that this effect is mostly driven by those Airbnb listings that are available for booking for larger parts of the year. Focusing the analysis on just these high-availability listings, we find an average effect of up to 13 cents per square meter per additional nearby Airbnb listing. This effect of high-availability listings is larger than most results found in the literature. Further, our analysis suggests heterogeneous effects across different districts in the city. The marginal effect of Airbnb listings on rents appears to be greater in districts with a lower Airbnb density. Additionally, our results suggest that the districts with a higher Airbnb density likely experienced a larger slowdown in rent increases due to the policy.

For our analysis, we use web scraped data of listed rentals in Berlin. We combine these data with web scraped data on Airbnb in the city. We further add data on various neighborhood characteristics such as points-of-interest and pollution.

In a first step, we analyze the direct impacts of the Zweckentfremdungsverbot-Gesetz (ZwVbG) in Berlin. The law took effect in May 2014 but included a transition period that ended in May 2016. Toward the end of this transition period (from here on, the "May 2016 reform"), we find an average decrease of approximately eight entire homes on Airbnb per square kilometer in Berlin. The law also received a major update that took effect in August 2018 (from here on, the "August 2018 reform"). This update requires hosts on Airbnb and similar platforms to show a registration number on their listings that can only be acquired from local authorities. As a consequence of this policy change, another large decrease in the number of Airbnb listings in the city is observed. This additional decrease amounts to approximately ten entire homes per square kilometer on average and is similar in size to the

\footnotetext{
${ }^{2}$ The top four European cities in descending order were London, Paris, Rome, and Copenhagen. Compare https://www.statista.com/statistics/815145/airbnb-listings-in-europe-by-city/ (accessed: July 3, 2020).
} 
first drop toward the end of the transition period. Both policy changes affected entire homes on Airbnb more strongly than other types of Airbnb listings. While the average decrease in the number of entire homes listed on Airbnb appears similar for each of these policy changes, they affected different groups of Airbnb listings. While the May 2016 reform led listings that were available for booking for large parts of the year to leave the platform, the August 2018 reform mostly caused low-availability listings to drop from Airbnb.

In a second step, we then use these policy changes as instruments to assess the impact of Airbnb on asked rents in the city. Our first step analysis suggests that the reforms are relevant instruments, at least in short windows around the changes. Therefore, we focus on seven-month windows around the policy changes in our main analyses. To deal with the large number of potential covariates and model selection, we employ double Lasso methods suggested by Belloni et al. (2014) and Chernozhukov et al. (2015). To quantify Airbnb presence in this analysis, we count the number of entire homes listed on Airbnb within 250 meters of each rental apartment. We find that Airbnb indeed causes rent increases. Our base specifications suggest rent increases of seven to ten cents per square meter per additional nearby entire home on Airbnb. However, when we focus on only those Airbnb listings that are available for booking for at least 180 days in a year, the estimated marginal effect lies at ten to 13 cents per square meter.

In a third step, we repeat the main analysis but stratify the sample by districts. Our results suggest substantial effect heterogeneity with effect sizes of up to 46 cents per square meter for each additional nearby Airbnb. We find suggestive evidence that those districts with a lower Airbnb density experience larger marginal rent increases per Airbnb on average. In an additional exercise, we then calculate what our first- and second-stage estimates imply for the cumulative effect of the law on rents in the different districts of the city. While we find lower marginal effects of Airbnb in districts with a higher Airbnb density, these same districts experienced a larger decrease in the number of Airbnb listings. Combining the firstand second-stage results of our heterogeneity analysis, we find that districts with a higher Airbnb density likely experienced a larger slowdown in rent increases due to the policy.

Our research contributes most directly to the literature trying to assess the causality between Airbnb and the housing market. Horn and Merante (2017) assess the impact of Airbnb on listed rents in Boston. They find that a one standard deviation increase in Airbnb listings increases rents by an average of 0.4 percent. The effect is particularly strong for 
apartments with two or more rooms. Further, they find evidence suggesting that this effect is driven by a decrease in rental supply. To address endogeneity, their analysis is based on observable variables and lagged Airbnb numbers to address omitted variable bias and/or reverse causality. Barron et al. (2020) analyze the impact of Airbnb on rents and house prices in the US. Using a shift-share instrumental variable approach, they find that a one percent increase in Airbnb listings increases rents by 0.018 percent and house prices by 0.026 percent on average. Garcia-López et al. (2019) use a panel fixed-effects specification as well as a shift-share instrumental variable approach similar to Barron et al. (2020) and find that rents and house prices in Barcelona increased as Airbnb listings became more widespread. Koster et al. (2018) and Valentin (2020) are the only papers that we are aware of that use policy changes as natural experiments for identification. Koster et al. (2018) analyze the impact of Airbnb on house prices and rents in Los Angeles County. They use the fact that several cities in the county started regulating short-term accommodations at different points in time to estimate an RDD model around city borders. They show that the regulation reduced Airbnb listings by approximately 50 percent. In their main results, they further show that this regulation reduces property prices by three percent. In additional estimations at the ZIP-code level, they also find that rents decreased by three percent on average. Valentin (2020) analyzes the introduction of short-term rental regulation in New Orleans, showing that a ban on short-term rentals decreased house prices by 30 percent.

We proceed as follows. In Section 2, we present institutional details about the regulation of Airbnb in Berlin. Further, we describe the different data sets used in the analysis. In Section 3, we provide first descriptive analyses. In Section 4, we discuss our identification strategy and other methodological issues. In Section 5, we show our main results. In Section6, we perform robustness checks. In Section 17, we examine the heterogeneity of our results. Section 8 concludes.

\section{Institutional Details and Data}

Airbnb is a peer-to-peer accommodation platform that was founded in 2008. As of June 2020, hosts offer accommodations in more than 220 countrie: 3 . Airbnb hosts can decide to offer a shared room, a private room, or a full accommodation for rent. Since September 2019, Airbnb also features hotel rooms.

\footnotetext{
${ }^{3}$ See https://press . atairbnb.com/about-us/ (accessed June 8, 2020).
} 
Many cities around the world have introduced laws to regulate Airbnb over the years. In Berlin, regulation was introduced with the ZwVbG, which was passed on December 12, 2013. This original law only introduces the option to declare a ban on the misuse of apartments for purposes other than long-term rental in areas in Berlin where a sufficient supply of housing is at risk. The law defines several cases that would constitute misuse, among which there are short-term renting, commercial use, and long-term vacancy. For our analysis, the most relevant misuse case is short-term renting. If such a ban is declared, misuse of apartments would only be allowed with permission from local district authorities. In the original version of the law, it was not clearly defined which misuse cases would still be allowed.

On March 4, 2014, the Berlin Senate passed a decree to implement the ZwVbG in Berlin. The decree declared that the supply of housing is at risk across the entire city of Berlin and, therefore, a ban on the misuse of apartments took effect in May 2014. However, the ZwVbG included a two-year transition period during which cases that would be defined as misuse under the law but that were already active before May 2014 would still be permitted. This transition period ended in May 2016. Thereafter, short-term renting would only be allowed with a permit issued by the district in which the apartment is located.

On April 20, 2018, an updated version of the law was passed. This update took effect on August 1, 2018. A major change included was that hosts on Airbnb and similar platforms are now required to display a registration number. In order to obtain this registration number, permission to sublet the apartment has to be obtained from the district. At the same time, the update more clearly defines cases for which permission for short-term renting is to be granted. In particular, residents who would like to rent out their main residence during their own absence are now allowed to do so, as long as the status of the apartment as their main residence is not affected. Furthermore, residents can now also permanently rent out parts of their apartments if these parts make up less than 50 percent of the living space. Secondary residences now qualify for a permit if they are used as short-term accommodation for no more than 90 days per year. Figure 1 summarizes the different stages of the law.

For our analysis, we focus on the end of the transition period in May 2016 as well as on the update of the law in August 2018. We refer to these policy changes as the "May 2016 reform" and the "August 2018 reform."

For our analysis, we combine data from multiple sources. To measure rents, we use 
May 1, 2014: May 1, 2016: April 20, 2018: August 1, 2018:

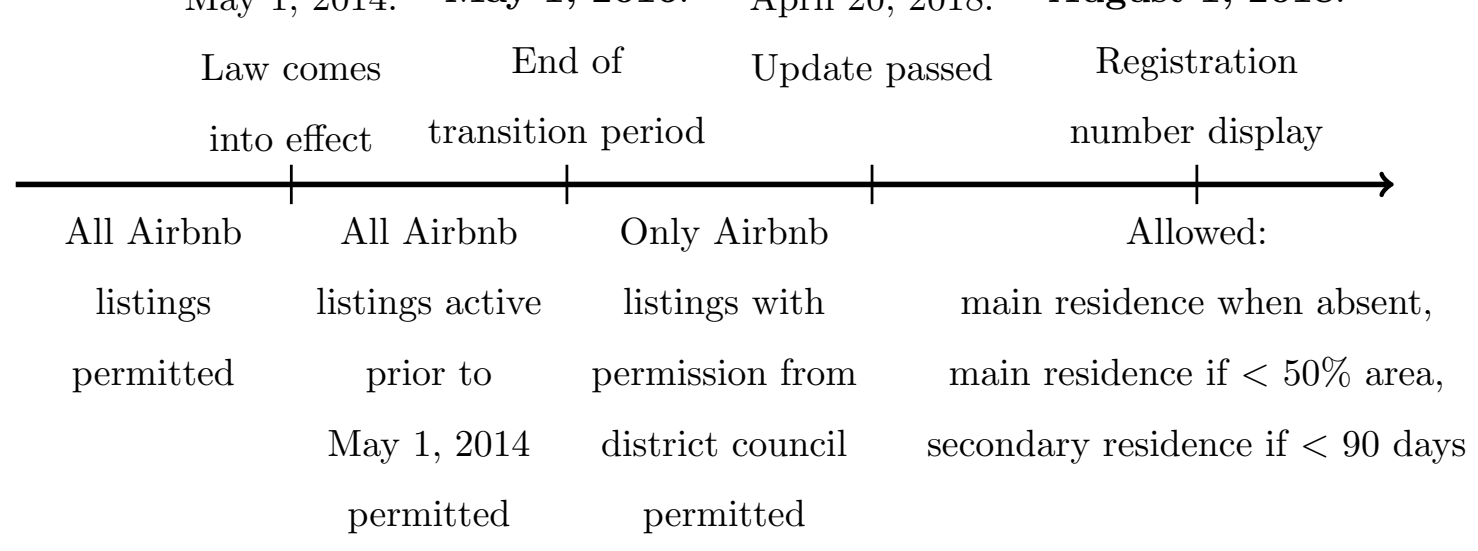

Figure 1: Stages of the ZwVbG. Dates in bold denote the policy dates used in our analysis.

data provided to us by Empirica, an economic consultancy 44 The data include web scraped information of asked rents for apartments listed in Berlin. The full data set features all rental apartments listed from January 2013 through July 2019. Besides rents, the data also contain various apartment characteristics, such as the size of the apartment and the number of rooms, all of which might be important for explaining rents.

To assess the number of Airbnb listings in Berlin over time, we use data that is publicly available on the website InsideAirbnb as well as data provided by Tom Slee, Both sources provide monthly snapshots of web scraped data of Airbnb listings for multiple cities in the world. Data for Berlin are available in monthly intervals from May 2014 to May 2020, however with several gaps inbetween.

To account for heterogeneity in the attractiveness of different neighborhoods, we use geographical data from OpenStreetMap. The data include geographic information for various types of points-of-interest such as bus stops, restaurants, and supermarkets 5 Note that the data we use are a snapshot as of February 2018 and, thusly, offer only cross-sectional variation. Further, we use data provided by the city of Berlin that include various variables at a local level such as the amount of noise at night or the level of particulate matter in the air 6 Again, these data are only of cross-sectional nature.

Our analysis uses data aggregated at two different levels of aggregation. In our main analysis, we use data on a disaggregated level. Each observation constitutes one rental in the

\footnotetext{
${ }^{4}$ See https://www .empirica-institut.de/en/company-profile/.

${ }^{5}$ The data are available at https://download.geofabrik.de/europe/germany/berlin.html.

${ }^{6}$ The data are available at https://fbinter.stadt-berlin.de/fb/index.jsp
} 
month in which it was first listed for rent. This granular perspective has several advantages. First, it allows us to directly use the various apartment characteristics that are included in our rent data to account for aspects that might impact rents. Second, we can use information on the distribution of Airbnb listings in the city in a more detailed manner. More specifically, to measure Airbnb exposure, we count all entire homes listed on Airbnb in a circle of 250 meter radius surrounding each apartment.7 For the main analysis, we focus on entire homes listed on Airbnb because we expect these to have the largest effect on rents 8 Figure 2 illustrates the calculation of our measure of Airbnb exposure.

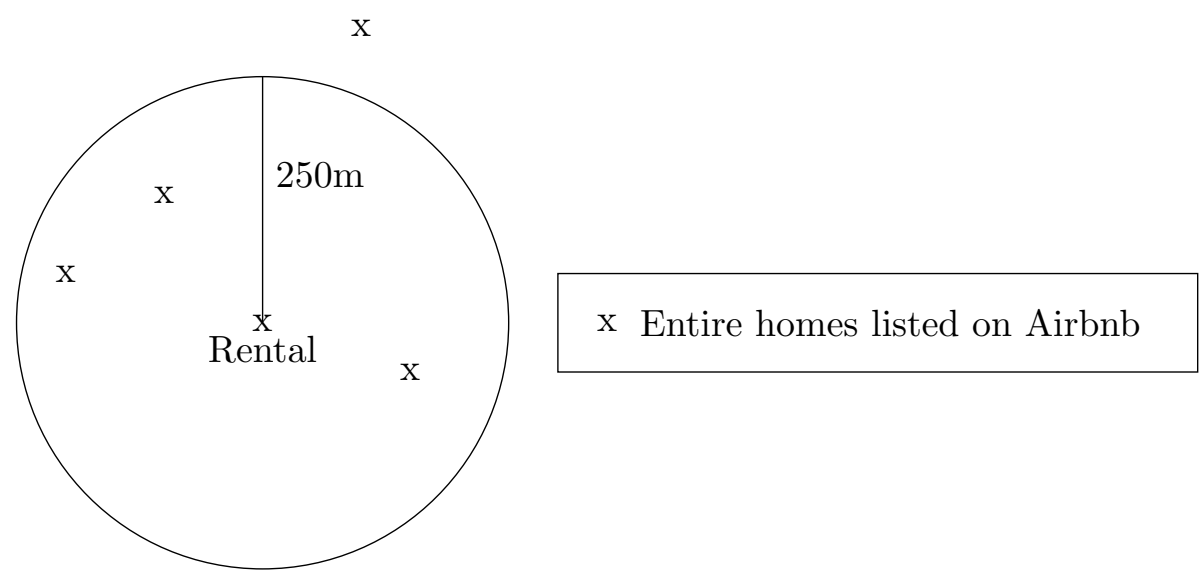

Figure 2: Illustration of our measure for Airbnb exposure. In this example, the listing would be assigned to have three Airbnb listings nearby.

In additional analyses, we aggregate the disaggregated data set to geographical areas called "Lebensweltlich orientierte Räume" (LOR). LOR are statistical areas defined and used by the city of Berlin. They are supposed to capture areas that are similar in livelihood. As of January 2019, the city of Berlin is divided into 448 different LOR.9 This aggregated

\footnotetext{
${ }^{7}$ The choice of a radius of $250 \mathrm{~m}$ is ad-hoc. A trade-off is involved: On the one hand, we expect Airbnb listings that are closer to an apartment to have a larger impact on rents. On the other hand, the location of each Airbnb listing is shifted by up to $150 \mathrm{~m}$ (see http://insideairbnb.com/about.html (accessed: June 8, 2020)). Larger circle sizes would therefore decrease the importance of the resulting measurement error. Using larger Airbnb circle sizes reduces the effect sizes that we find, in line with our intuition. We report these results in Section 6.2

${ }^{8}$ If we use private or shared rooms, our main estimates are qualitatively similar, but noisier. One reason for this imprecision is that the policy reforms did not affect these other Airbnb categories as much.

${ }^{9}$ See https://www.stadtentwicklung.berlin.de/planen/basisdaten_stadtentwicklung/lor/ (accessed June 8, 2020).
} 
perspective allows us to conduct additional analyses, such as assessing the impact of the policy changes on the number of rentals listed in the city.

Because we want to use detailed geographical information in our main analysis, we restrict our sample to those rentals for which exact address information is available. This is the case for approximately 80 percent of the data set. Because the data do not include coordinates, we use the address information to geocode the location of each rental. This could be done without any issues for approximately 95 percent of the rentals for which we have the full address information. We exclude the rest. This leaves us with approximately 76 percent of the original observations $(212,831$ observations for the full sample).

Our main analyses focus on the policy changes of May 2016 and August 2018. We conduct our main analyses for seven-month time windows around these two policy changes (three pretreatment months, three post-treatment months, and the treatment month).

\section{Descriptives}

To better understand our data, we provide various descriptive analyses in this section. We start with some descriptive results on the Airbnb level. We continue at the rental-month level, which is the level of observation in our main analyses. Finally, we present descriptive statistics at the LOR level.

\subsection{Airbnb Descriptives}

To illustrate the characteristics of Airbnb in Berlin, we first provide some descriptives on the Airbnb level. Generally, the number of Airbnb listings in the city is increasing. However, the two policy changes in May 2016 and in August 2018 had a clear impact on the number of available Airbnb listings in the city. These impacts are shown in Figure 3. This figure shows the number of Airbnb listings available in the city at each of the monthly snapshots, decomposed by the type of Airbnb listings ${ }^{10}$

Over most of the observation period, the number of Airbnb listings in the city is increasing, mostly because the number of entire homes and private rooms in the city is increasing. However, around both reforms, a clear drop in the number of Airbnb listings in the city is

\footnotetext{
${ }^{10} \mathrm{An}$ Airbnb listing is part of our data set if it appears as a result when searching for accommodations in Berlin without any date restrictions. This is the case if the listings is set to be available for booking at any time in the future.
} 


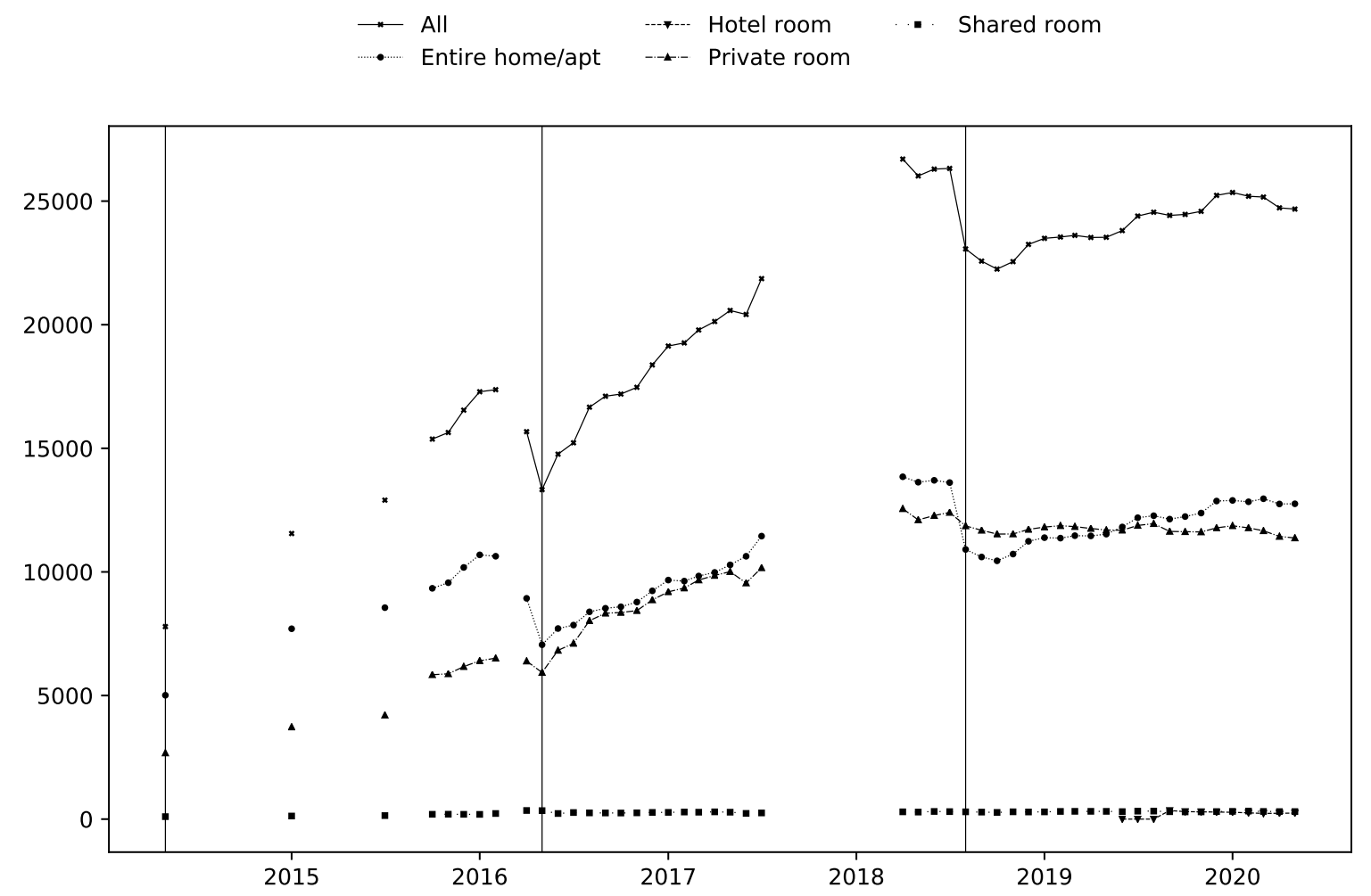

Figure 3: Number of Airbnb listings in Berlin over time

visible. Both drops are mostly driven by decreases in the number of entire homes. As a result, while the number of entire homes on Airbnb was approximately double the number of private rooms in the first monthly snapshot, they are approximately equal toward the end of the observation period. The clear drops around the dates that policy changes were implemented suggest that these changes in the structure of listings on Airbnb are, at least to some extent, driven by policy.

However, the reforms did not just decrease the number of Airbnb listings in the city. The law also affected average availability of listings on the platform. Figure 4 shows the average number of days per year that an Airbnb listing was available for booking in each of the monthly snapshots by Airbnb listing type.

Leading up to the May 2016 reform, the average availability decreases substantially across all listing types. After May 2016, the mean availability decreases further until the August 2018 reform. Here, the mean availability slightly increases, in particular for entire homes. Interestingly, the new mean in August 2018 seems to lie at an availability of around 90 days per year, which is the cut-off availability below which secondary apartments may also be 


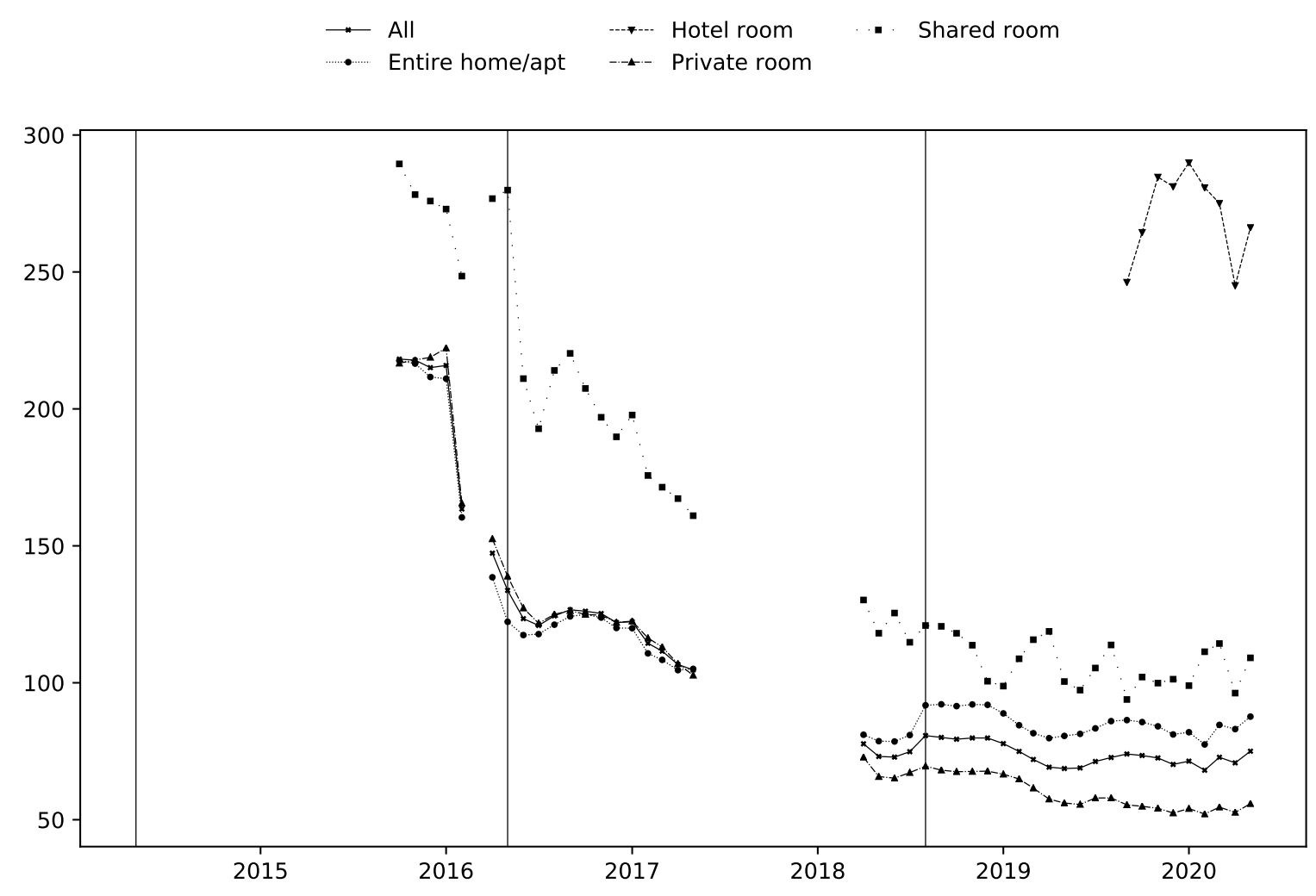

Figure 4: Mean availability per 365 days by type of Airbnb listing 
rented out as short-term rentals following the August 2018 update of the law (see Figure 1).

Therefore, while Figure 3 suggests that the two policy changes affected Airbnb in Berlin similarly, Figure 4 provides more nuance. The May 2016 reform seems to have had a particularly large effect on those Airbnb listings that were available for booking for larger parts of the year. This result is relevant for our main analysis. The main mechanism by which Airbnb is hypothesized to affect rents is that landlords decide to list apartments on Airbnb rather than renting them out long-term (e.g. Yrigoy, 2019). If this mechanism is true, we would expect those Airbnb listings that are listed as short-term rentals for larger parts of the year to impact rents more.

\subsection{Rental Descriptives}

In our main analysis, we use disaggregated data at the rental level. Each observation represents one long-term rental apartment in the month in which it was first listed online. Table 1 shows selected descriptive statistics calculated for the two samples that we use in our analysis. The "May 2016" sample includes observations from February 2016 to August 2016, while the "August 2018" sample includes data from May 2018 to November 2018. Note that Airbnb data is missing in March 2016.

The average net rent per square meter amounts to 9.24 Euro in the May 2016 sample and 10.86 Euro in the August 2018 sample. On average, each apartment had approximately 18 Airbnb listings within 250 meters in the May 2016 sample. This number increases to about 28 Airbnb listings in the August 2018 sample. In 2016, the largest group of Airbnb listings are entire homes. On average, each rental in the 2016 sample has ten nearby entire homes listed on Airbnb. The entire homes are followed by private rooms with an average of eight listings within 250 meters. In 2018, however, both types of Airbnb listings are approximately equally prominent with apartments having on average 13 of each nearby. Shared rooms make up only a small share of the Airbnb listings. The number of nearby Airbnb listings has large variance and is highly right-skewed. For example, in the May 2016 sample, the median apartment only has two nearby entire homes listed on Airbnb, whereas the apartment with the largest count features 119 nearby entire homes.

Figure 5 shows the evolution of the average net rent per square meter over time in the entire city in general and split by Airbnb density in February 2016. We use February 2016 as the base month because it precedes both of our treatment dates as well as the decrease in 
Table 1: Rental-level descriptive statistics

\begin{tabular}{lcccccc}
\hline \hline & $\mathrm{N}$ & Mean & Std. & Min. & $50 \%$ & Max. \\
\hline Sample: May 2016 & & & & & & \\
Monthly rent & 23027 & 656.45 & 400.11 & 100 & 542 & 6500 \\
Area (sqm) & 23027 & 70.26 & 30.24 & 11 & 64 & 470 \\
Rent per sqm & 23027 & 9.24 & 2.58 & 3 & 9 & 28 \\
Rooms & 23009 & 2.38 & 0.96 & 1 & 2 & 8 \\
\# Airbnb (all, 250m) & 19683 & 18.25 & 29.78 & 0 & 4 & 178 \\
... available $>180$ days & 19683 & 6.62 & 10.55 & 0 & 2 & 75 \\
\# Airbnb (entire homes, 250m) & 19683 & 9.97 & 17.04 & 0 & 2 & 119 \\
... available $>180$ days & 19683 & 3.63 & 6.30 & 0 & 1 & 53 \\
\# Airbnb (private rooms, 250m) & 19683 & 8.09 & 13.49 & 0 & 2 & 95 \\
... available $>180$ days & 19683 & 2.87 & 4.65 & 0 & 1 & 37 \\
\hline Sample: August 2018 & & & & & & \\
Monthly rent & 21356 & 755.92 & 466.13 & 122 & 630 & 11000 \\
Area (sqm) & 21356 & 68.88 & 29.74 & 15 & 63 & 551 \\
Rent per sqm & 21356 & 10.86 & 3.30 & 3 & 10 & 43 \\
Rooms & 21332 & 2.34 & 0.94 & 1 & 2 & 9 \\
\# Airbnb (all, 250m) & 21356 & 27.66 & 43.87 & 0 & 6 & 299 \\
... available $>180$ days & 21356 & 5.02 & 7.90 & 0 & 1 & 59 \\
\# Airbnb (entire homes, 250m) & 21356 & 13.56 & 22.66 & 0 & 3 & 152 \\
... available $>180$ days & 21356 & 2.91 & 5.16 & 0 & 1 & 47 \\
\# Airbnb (private rooms, 250m) & 21356 & 13.82 & 22.41 & 0 & 3 & 151 \\
.. available $>180$ days & 2.04 & 3.28 & 0 & 1 & 24 \\
\hline \hline
\end{tabular}

Notes: Descriptive statistics for selected variables on the rental-month level. The upper panel shows the descriptives for the sample surrounding the end of the transition period in May 2016. The lower panel shows the descriptives for the sample surrounding the start of the mandatory registration number display in August 2018. 


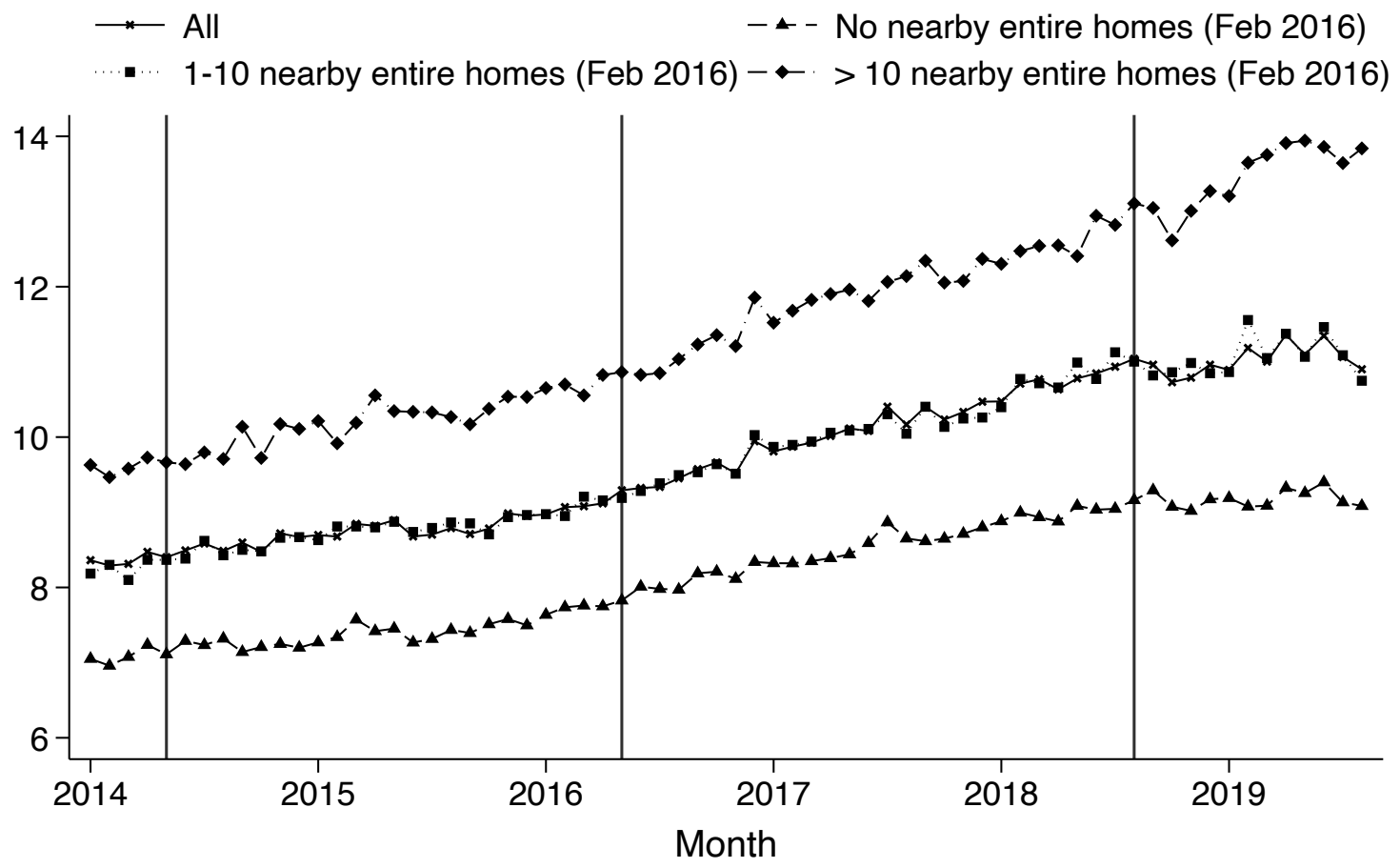

Figure 5: Average asked rent per square meter of newly listed rentals over time, split by locations with more, fewer, and no entire homes on Airbnb within a 250m distance in February 2016. The vertical lines indicate the policy dates: May 1, 2014; May 1, 2016; and August 1, 2018.

Airbnb listings before the May 2016 reform (see Figure 3). The lines show the average rent for all rentals listed in each month, all rentals at locations that did not have any nearby entire homes on Airbnb in February 2016, all rentals at locations that did have some nearby entire homes in February 2016, and all rentals at locations that had many nearby entire homes in February 2016. To classify the latter two groups, we split those locations with a positive Airbnb count in February 2016 at the median (at ten nearby entire homes). In general, rents are increasing over time. There are some fluctuations and, in particular, the August 2018 reform appears to be followed by a drop in average rents. However, given the variation in these means, it is not clear whether the policy change caused this drop.

Therefore, in Figure 6, we present a more refined view. For this figure, we conduct an analysis inspired by the main specification that Huber et al. (2019) employ in an entirely different context. We first need a measure of pre-treatment exposure to Airbnb. For this 
purpose, we count the number of entire homes within 250 meters, as of February 2016, for the location of each rental in the data. For rental $i$, denote this measure as $a b b(F e b 2016)_{i}$. The basic idea then is to interact this measure with a full set of quarter fixed effects and use these interactions in a regression to assess how the discrepancy in rents between areas with fewer and more Airbnb listings in February 2016 changes over time. This regression amounts to estimating the following equation:

$$
\begin{aligned}
y_{i q}= & \sum_{\tau=Q 1,2014}^{Q 3,2019} \beta_{\tau} a b b(F e b 2016)_{i} \times \mathbb{1}(q(i)=\tau)+\mathbb{1}(q(i)=\tau)+\text { District }_{i} \times \mathbb{1}(q(i)=\tau) \\
& + \text { DistrictF } E_{i}+c+\epsilon_{i t} .
\end{aligned}
$$

Each observation is one rental apartment in the quarter that it was first listed. $y_{i q}$ is the asked rent per square meter. $a b b(F e b 2016)_{i}$ denotes the number of entire homes within 250 meters of the location of rental $i$ in February 2016. We interact this cross-sectional measure of pre-treatment Airbnb exposure with a full set of quarter fixed effects. We use the first quarter of 2016 (the quarter containing February 2016) as the base quarter. Further, we include a full set of quarter fixed effects, district fixed effects, as well as the full set of interactions between quarter and district fixed effects. In Figure 6, we report the estimates of $\beta_{\tau}$ for all quarters. These estimates capture the difference in rents between rentals in locations with more and less Airbnb exposure in February 2016, conditional on the fixed effects.

The figure indicates that even conditional on this rich set of fixed effects, rents in areas with many Airbnb listings develop differently from those in areas with fewer Airbnb listings. The gap in average rents between low- and high-Airbnb areas seems to be increasing over time. However, the figure also indicates that following the May 2016 reform, there seems to be a temporary break in this trend. This indicates that the law may have had an effect on rents by slowing the growth in areas with more Airbnb listings pre-treatment. However, this effect seems to be transitory as the discrepancy in rents increases again in late 2018 .

The plot also suggests that there seem to be other unobserved factors that affect the relationship between Airbnb and rents. These factors make identification, especially in a long-term analysis such as conducted for Figure 6, difficult. These insights further motivate why we focus our main analyses on short seven-months windows around the two reforms. With these shorter windows, we can ensure that we better capture the effect of the treatments on Airbnb presence and, consequently, the causal impact of Airbnb on rents. 


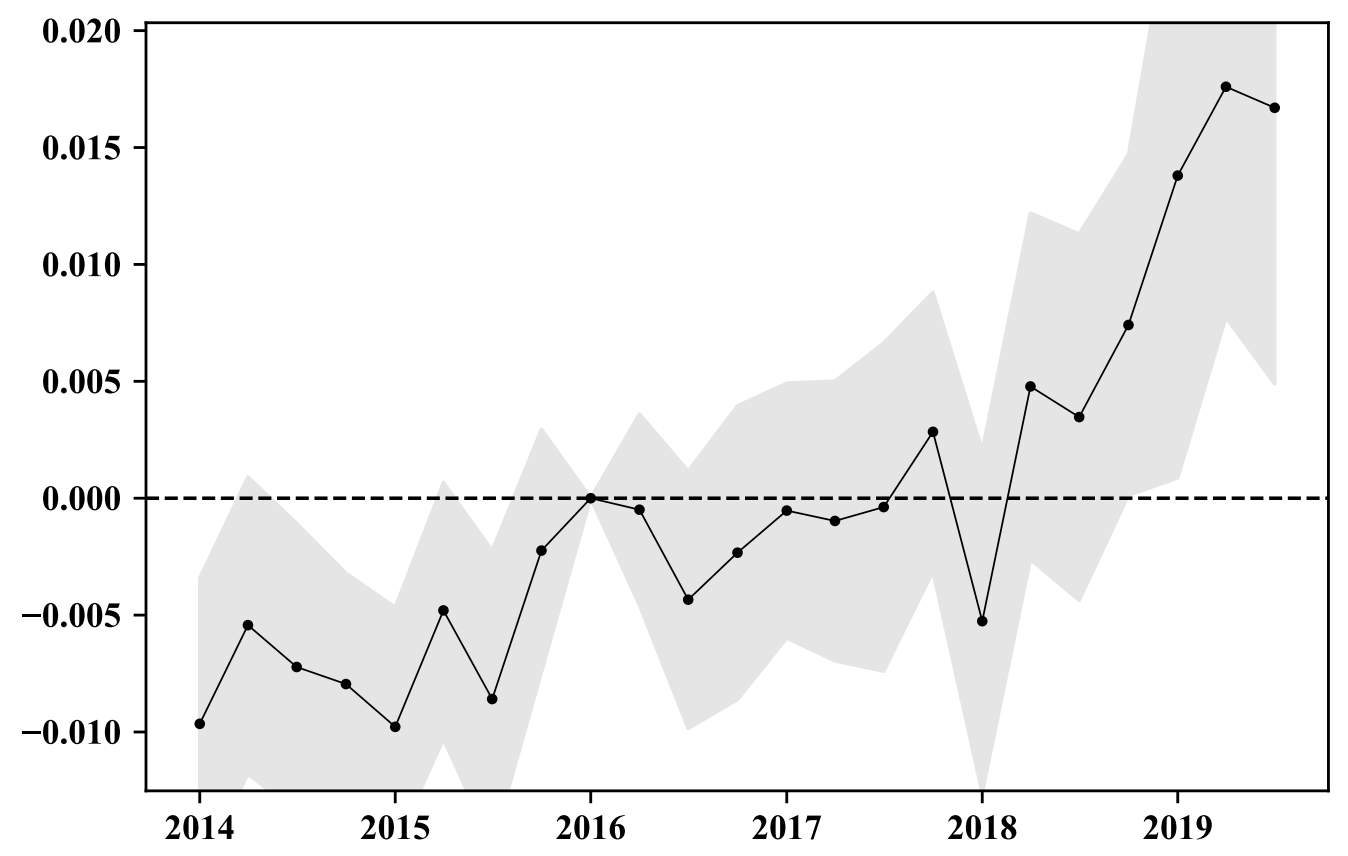

Figure 6: Point estimates of $\beta_{\tau}$ from equation (1). Shaded areas indicate 95 percent confidence intervals. 
Table 2: LOR-level descriptive statistics

\begin{tabular}{lcccccc}
\hline \hline & $\mathrm{N}$ & Mean & Std. & Min. & $50 \%$ & Max. \\
\hline Sample: May 2016 & & & & & & \\
Rentals per $\mathrm{km}^{2}$ & 2771 & 9.01 & 9.31 & 0 & 6 & 91 \\
Airbnb per $\mathrm{km}^{2}$ & 2375 & 52.65 & 104.37 & 0 & 6 & 786 \\
Entire homes per $\mathrm{km}^{2}$ & 2375 & 28.53 & 58.21 & 0 & 3 & 447 \\
Private rooms per $\mathrm{km}^{2}$ & 2375 & 23.42 & 48.07 & 0 & 3 & 446 \\
Shared rooms per $\mathrm{km}^{2}$ & 2375 & 0.70 & 2.08 & 0 & 0 & 31 \\
\hline Sample: August 2018 & & & & & & \\
Rentals per $\mathrm{km}^{2}$ & 2738 & 8.42 & 8.60 & 0 & 6 & 77 \\
Airbnb per $\mathrm{km}^{2}$ & 2738 & 82.99 & 158.75 & 0 & 10 & 1068 \\
Entire homes per $\mathrm{km}^{2}$ & 2738 & 40.62 & 80.00 & 0 & 5 & 589 \\
Private rooms per $\mathrm{km}^{2}$ & 2738 & 41.43 & 81.79 & 0 & 5 & 598 \\
Shared rooms per $\mathrm{km}^{2}$ & 2738 & 0.95 & 2.71 & 0 & 0 & 47 \\
\hline \hline
\end{tabular}

Notes: Descriptive statistics for selected variables on the LOR-month level.

The upper panel shows the descriptives for the sample surrounding the end of the transition period in May 2016. The lower panel shows the descriptives for the sample surrounding the start of the mandatory registration number display in August 2018.

\subsection{LOR-level Descriptives}

In additional analyses, we aggregate the rental-level data set to the LOR level. Each observation represents one LOR in one month. Table 2 shows some descriptive statistics on the LOR-level.

This LOR-level perspective is particularly interesting when analyzing the number of Airbnb listings and rentals in the city rather than rents. On average, there are about eight to nine rentals listed per square kilometer in each month. The average number of Airbnb listings is larger with an average of 53 Airbnb listings per square kilometer around May 2016 and 83 Airbnb listings per square kilometer around August 2018. The numbers of entire homes, private rooms, and shared rooms develop similarly as in the disaggregated data set.

Figure $7 \mathrm{a}$ shows the average number of rentals per $\mathrm{km}^{2}$ per month in the city by LOR 
Table 3: Airbnb, rents, and rental supply

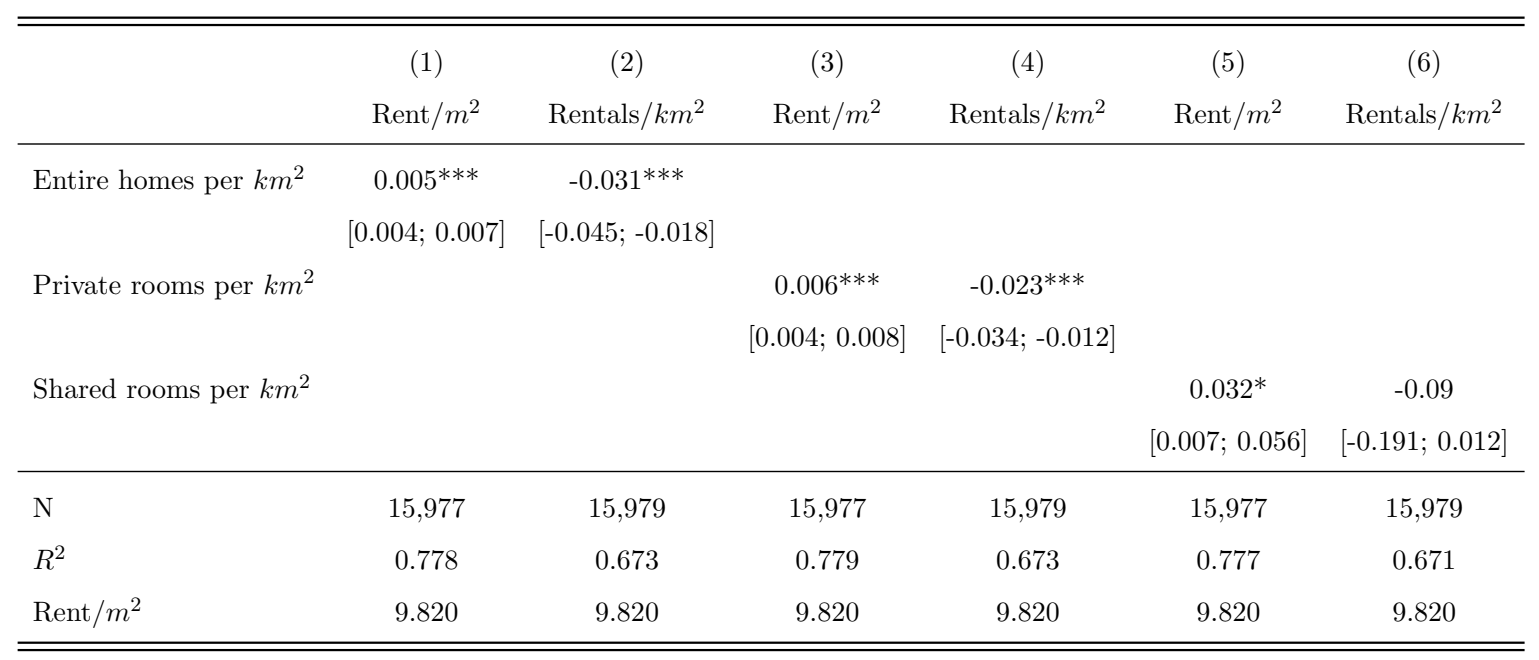

Notes: LOR-level regressions using OLS for all months for which Airbnb data is available. The regressions include LOR fixed effects and a linear time trend. Regressions with rent $/ \mathrm{m}^{2}$ as dependent variable also include LOR-month-level mean apartment characteristics. The square brackets show 95 percent confidence intervals. *,**, *** indicate five, one, 0.1 percent significance.

calculated over the entire data set. The rental density appears to be somewhat higher closer to the city center. But there are also various outskirts that have higher rental densities. Figure $7 \mathrm{~b}$ shows a heat map of the average number of entire homes on Airbnb per square kilometer by LOR calculated over the entire data set. Compared to the rentals, entire homes on Airbnb are more concentrated in the city center.

The total number of rentals listed in the city each month fluctuates over time. Figure 8 shows the number of newly listed rentals in Berlin over time. Looking at the line for the time around the policy changes (indicated by the second and third vertical lines) may suggest an increase in rental supply following the policy changes. However, as was the case for the average rents, the large fluctuation of the means does not allow for conclusive statements based on this graphical analysis alone.

We next conduct an analysis of the partial correlation of available Airbnb listings with rents and the supply of long-term rentals in Berlin. Since this analysis is not focused on the impacts of the policy changes, we use the entire sample for which both Airbnb and rent data are available. As Figures 3 and 5 show, this sample includes data from May 2014 to August 2019. Table 3 reports the results of the regressions.

The results show a positive correlation of Airbnb density with rents for all types of Airbnb listings. It also suggests a negative correlation between the density of Airbnb listings with 


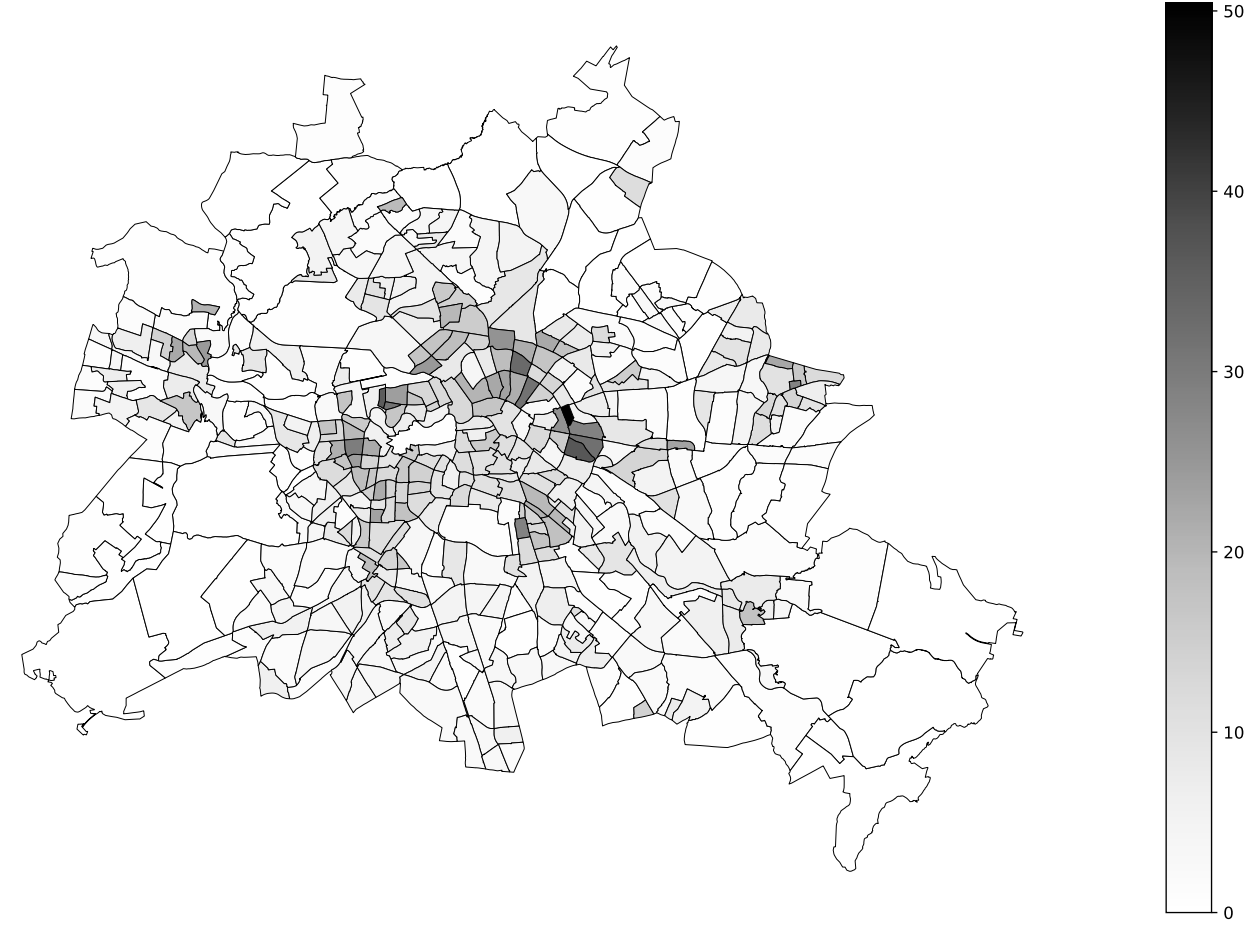

(a) Rentals per $k m^{2}$
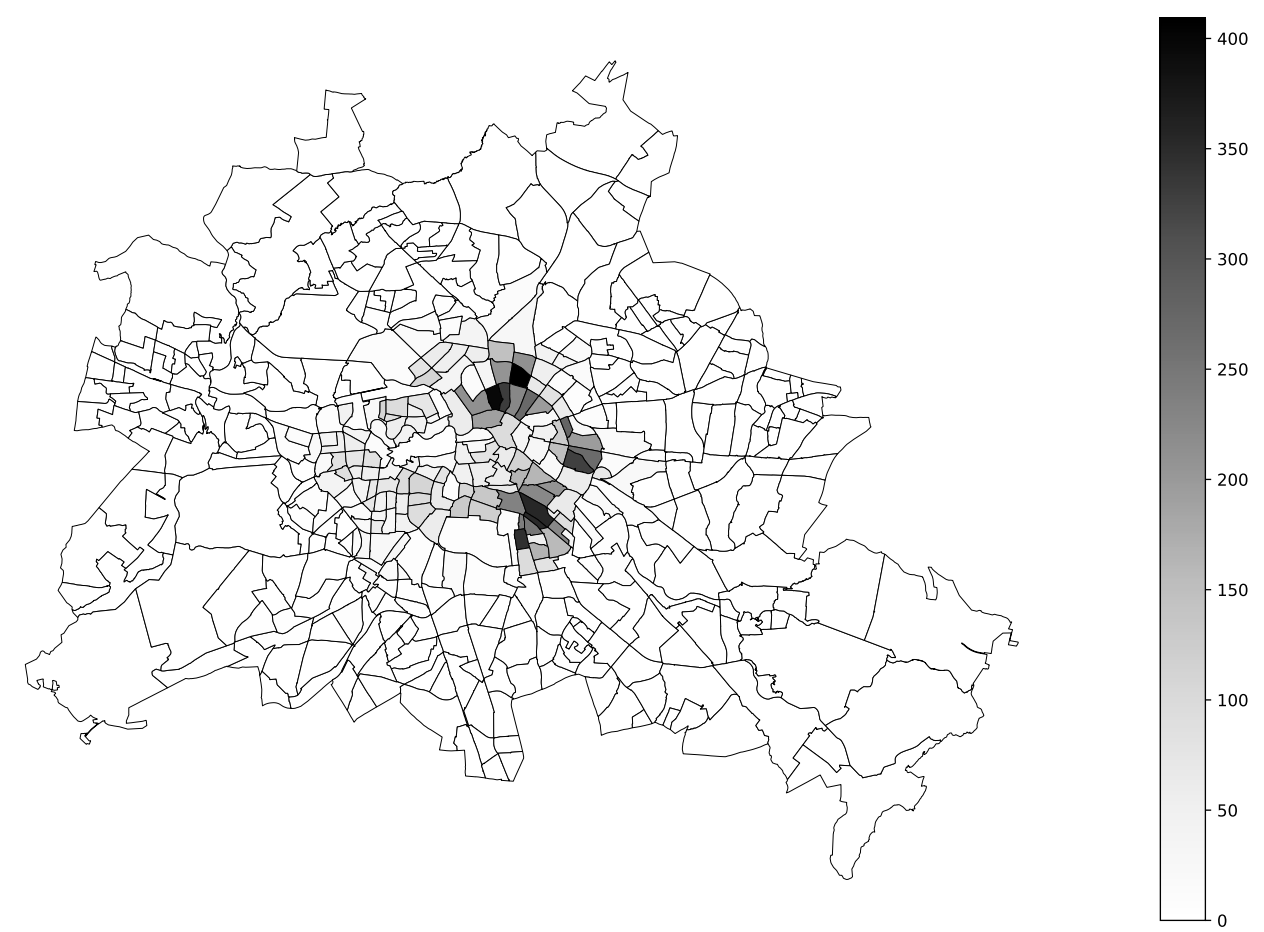

(b) Entire homes on Airbnb per $\mathrm{km}^{2}$

Figure 7: Heat maps of the average number of long-term rentals and entire homes on Airbnb per square kilometer by LOR for the entire data set 


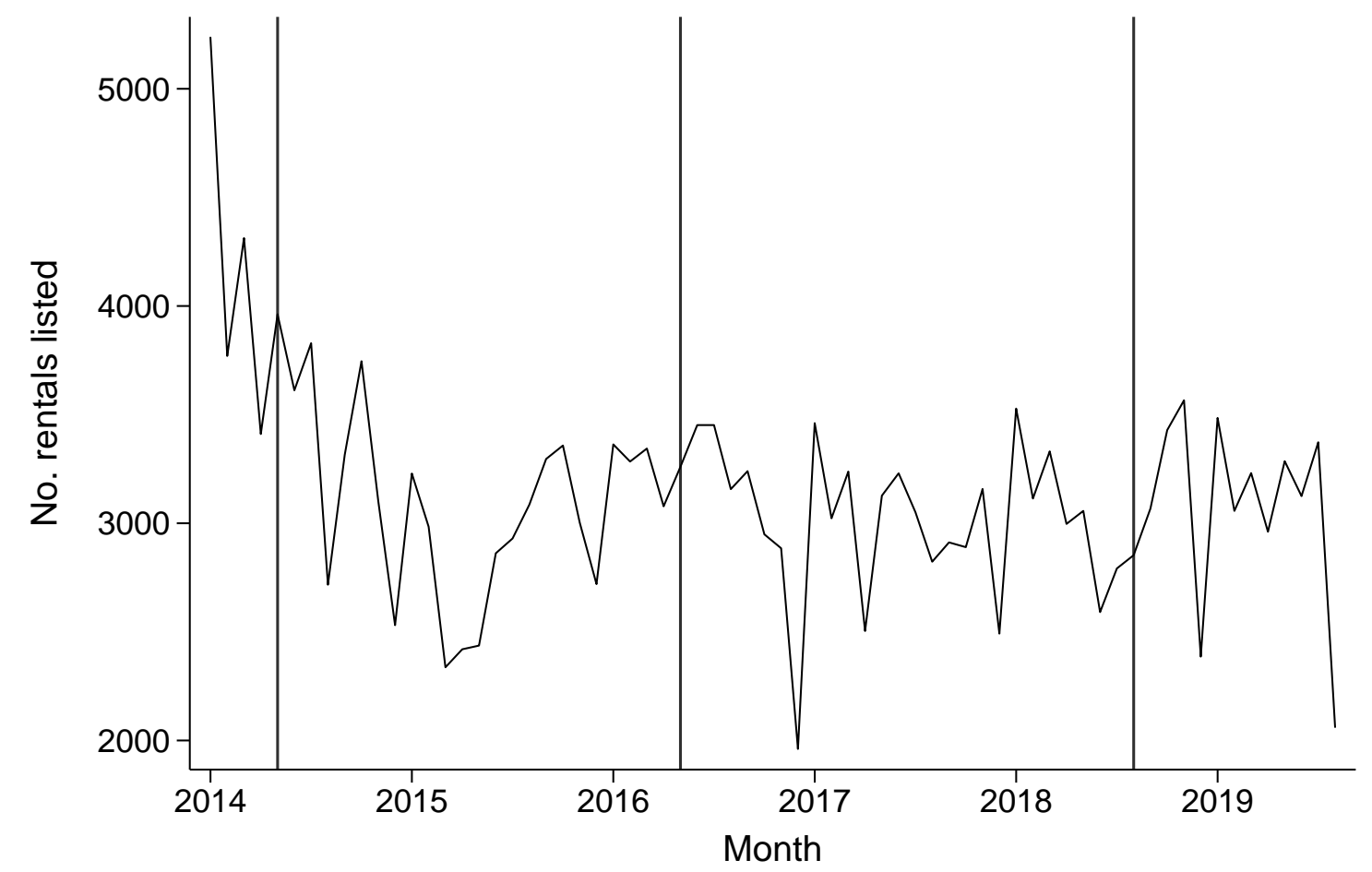

Figure 8: Newly listed rentals over time. The vertical lines indicate the policy dates: May 1, 2014, May 1, 2016, and August 1, 2018. 
rental density for all types of Airbnb listings. However, the point estimate for shared rooms is quite noisy and not statistically significant at conventional significance levels. These correlations are in line with the intuition for the mechanism of why Airbnb might have an effect on rents: apartments listed as short-term rentals are removed from the long-term rental market, thereby reducing supply, which results in increasing prices.

\section{Identification Strategy and Estimation Methods}

To analyze the impact of Airbnb on rents, a naive approach is to regress rents on some measure of Airbnb exposure and other covariates:

$$
y_{i t}=\alpha a b b_{i t}+x_{i t}^{\prime} \beta+\epsilon_{i t} .
$$

In our case, $y_{i t}$ is the asked monthly rent per square meter for rental $i$ listed in month $t, a b b_{i t}$ is the number of entire homes listed on Airbnb within 250 meters of the rental, and $x_{i t}$ is a vector of exogenous control variables.

\subsection{Identification Strategy}

Estimation of Equation (2) potentially suffers from endogeneity problems. Arguably most relevant to this particular question are omitted variable bias and reverse causality. Omitted variable bias is an issue if there are unobserved characteristics that affect the attractiveness of an area for both residents as well as tourists and, therefore, would drive both changes in rents as well as in the incentives to host a listing on Airbnb. Reverse causality might be an issue if increasing rents cause residents to list their apartments on Airbnb to subsidize part of their rent. Thus, to establish causality, an identification strategy is needed to address these concerns.

To address the identification concerns, we use the reforms induced by the $\mathrm{ZwVbG}$ as quasiexperiments. More specifically, we use these policy changes as instruments in an instrumental variable regression. We also include a potentially large set of covariates to account for apartment characteristics, neighborhood characteristics, as well as postal code level cross-sectional differences in attractiveness. In our main analysis, we therefore estimate

$$
\begin{gathered}
y_{i t}=\alpha a b b_{i t}+x_{i t}^{\prime} \beta+\epsilon_{i t} \\
a b b_{i t}=\gamma \mathbb{1}(t \geq l a w)+x_{i t}^{\prime} \delta+u_{i t},
\end{gathered}
$$


where $y_{i t}$ is the asked monthly rent per square meter for rental $i$ listed in month $t, a b b_{i t}$ is a measure of Airbnb listings within 250 meters of the rental, $x_{i t}$ is a set of exogenous control variables and $\mathbb{1}(t \geq$ law $)$ is an indicator variable that is one for observations after the date law (we refer to this variable as the "post-dummy"). We run separate regressions using both the end of the transition period on May 1, 2016 as well as the start of the mandatory registration number display on August 1, 2018, as cut-off dates. Thus, the variable law is either May 1, 2016, or August 1, 2018. In the base specification, $a b b_{i t}$ is the number of nearby entire homes listed on Airbnb but we also present results for different measures to illustrate some nuances of the effect of Airbnb on rents. We also include results in which we interact $\mathbb{1}(t \geq$ law $)$ with postal code fixed effects to allow for more heterogeneity in the first stage.

In order for the policy dummy to be a valid instrument, we need to assume that it is relevant and exogenous conditional on $x_{i t}$. We cannot directly test the exogeneity assumption. However, we are confident that there was no parallel policy change that might have affected rents $\sqrt{11}$ Figure 3 shows a clear drop in the number of Airbnb listings, in particular of entire homes, toward both policy dates. These drops already suggest that the instrument is relevant but we can formally test this using the first-stage regression of Equation (4).

In our main analyses, we focus on seven-month time windows around the two reforms. This short-term analysis increases the relevance of our instruments, because as Figure 3 suggests, there seem to be long-term trends and other factors that influence the number of Airbnb listings in the city over time. Additionally, the short-term focus helps with identification: Reverse causality is likely less relevant to drive joint changes in rents and Airbnb supply in the short run. Thus, we are mainly concerned with omitted variable bias from unobserved factors that cause both rents and Airbnb supply to change differently in certain regions compared to others. Thus, the direction of the bias of a naive approach, as in Equation (2), depends on the direction of both the conditional correlation between changes in Airbnb supply and the unobserved factor as well as the impact of the unobserved factor on changes in rents. Typically, in our context, we would expect unobserved factors to cause a steeper increase in rents in more popular areas, coupled with a larger increase in the supply of Airbnb listings. This would imply a positive bias and the naive approach would overestimate the effect of Airbnb on rents. Note that in our main analysis, we include postal code fixed effects as well

\footnotetext{
${ }^{11}$ Germany did introduce a rent ceiling for new rentals, but this policy took effect earlier in Berlin, in June 2015. For more details on this rent control policy, please see Mense et al. (2017).
} 
as various cross-sectional neighborhood characteristics. Thus, level differences in rents across different regions in Berlin are accounted for. Identification of the Airbnb effect then mostly comes from variation in rents and Airbnb numbers within given regions of the city during our sample period. Since the variation in Airbnb listings in our samples results mostly from a decrease in Airbnb listings, the direction of the bias described above would reverse in our analysis: The decrease in Airbnb listings is likely more pronounced in more popular areas (since those areas have a higher Airbnb density to begin with). Simultaneously, rents in these areas likely still increase more strongly than in less popular areas even if the Airbnb regulation dampens the growth somewhat. Consequently, the naive approach would underestimate the effect of Airbnb on rents. This is exactly what we find in our main analysis.

\subsection{Model Selection}

Equation (2) illustrates another relevant issue in our context. Because we have rich data on apartment and neighborhood characteristics, we have a potentially large vector $x_{i t}$. Including all our covariates would likely result in overfitting of the data, if not dimensionality problems. However, excluding covariates that correlate with both rent and the number of nearby Airbnb listings would introduce an omitted variable bias. Therefore, we need to deal with model selection carefully. To do so, we employ the "double-Lasso" estimators proposed by Belloni et al. (2014) for exogenous regressors and Chernozhukov et al. (2015) for instrumental variables estimation.

The basic idea of these methods is to use Lasso regression to select those covariates that are most important to explain the dependent variable as well as the explanatory variables of interest. In the most straightforward approach, the union of the sets of selected variables could then be used as covariates in the main regression. Chernozhukov et al. (2015) extend this approach. The authors propose an algorithmic estimator that is consistent and robust to small selection errors under certain assumptions. Arguably the most import assumption is that the true underlying model is "approximately sparse." This assumption requires that the true model can be approximated with a small number of variables with only little approximation error. For more details on how we apply the estimator in our context, please refer to Appendix A.1.

This estimator allows us to avoid the usual issues associated with model selection. In principle, as we are agnostic about which of the many covariates to include in the estimation, 
Table 4: Impact of ZwVbG on Airbnb in Berlin

\begin{tabular}{lcccccc}
\hline \hline & $(1)$ & $(2)$ & $(3)$ & $(4)$ & $(5)$ & $(6)$ \\
& Entire Homes & Entire Homes & Private Rooms & Private Rooms & Shared Rooms & Shared Rooms \\
& 2016 & 2018 & 2016 & 2018 & 2016 & 2018 \\
\hline Post-dummy & $-7.733^{* * *}$ & $-9.733^{* * *}$ & $-3.839^{* * *}$ & $-1.669^{* * *}$ & -0.05 & -0.032 \\
& {$[-9.656 ;-5.811]$} & {$[-12.180 ;-7.284]$} & {$[-4.803 ;-2.874]$} & {$[-2.432 ;-0.907]$} & {$[-0.138 ; 0.037]$} & {$[-0.121 ; 0.058]$} \\
\hline $\mathrm{N}$ & 2,375 & 2,738 & 2,375 & 2,738 & 2,375 & 2,738 \\
$R^{2}$ & 0.971 & 0.977 & 0.976 & 0.997 & 0.894 & 0.958 \\
Rent $/ m^{2}$ & 9.050 & 10.57 & 9.050 & 10.57 & 9.050 & 10.57 \\
\hline \hline
\end{tabular}

Notes: LOR-level regressions of the number of Airbnb listings per $\mathrm{km}^{2}$ in each LOR on the post-dummy. The square brackets show 95 percent confidence intervals. *, **, *** indicate five, one, 0.1 percent significance.

we let the algorithm decide which specification to use and report.

\section{Results}

Before presenting the results of the instrumental variable regression, we start with several preliminary analyses. These analyses are useful for shedding light on the impacts of the reforms on Airbnb and the rental market. We begin with analyses using data aggregated to the LOR-month level. This geographic aggregation allows us to not only investigate prices but also the number of Airbnb listings per $\mathrm{km}^{2}$.

\subsection{Direct Impacts of $\mathrm{ZwVbG}$}

The first set of results assesses the direct impacts of the policy changes due to ZwVbG on various outcomes in the Airbnb and rental markets. For this purpose, we focus on the aforementioned seven-month windows around the policy changes. Table 4 shows the results of a regression of Airbnb density on the post-dummies for all Airbnb listing types for both policy changes. The estimation for entire homes is equivalent to the first-stage regression we will conduct for the main analysis, except that here, it is conducted at the LOR level. These results confirm formally what an inspection of Figure 3 already suggested: Both policy changes resulted in large drops in the number of Airbnb listings in Berlin. These drops are particularly driven by decreases in the number of entire homes listed on Airbnb.

Following the May 2016 reform, the number of entire homes per square kilometer decreased 
Table 5: Impact of ZwVbG on availability of entire homes on Airbnb in Berlin

\begin{tabular}{lcccc}
\hline \hline & $(1)$ & $(2)$ & $(3)$ & $(4)$ \\
& 2016 & 2016 & 2018 & 2018 \\
& All & Balanced & All & Balanced \\
\hline Post-dummy & $-11.53^{* * *}$ & $-4.9^{* * *}$ & $7.74^{* * *}$ & -1.037 \\
& {$[-14.290 ;-8.781]$} & {$[-6.696 ;-3.104]$} & {$[5.710 ; 9.769]$} & {$[-2.108 ; 0.033]$} \\
\hline $\mathrm{N}$ & 50,381 & 26,621 & 83,456 & 52,351 \\
$R^{2}$ & 0.090 & 0.130 & 0.105 & 0.150 \\
\hline \hline
\end{tabular}

Notes: Airbnb-level regressions of availability per 365 days on the post law dummy for entire homes only. "Balanced" includes only listings that are observed in the entire sample. The square brackets show 95 percent confidence intervals. ${ }^{*}, * *, * * *$ indicate five, one, 0.1 percent significance.

by almost eight on average. Table 2 shows that the sample mean of entire homes per square kilometer amounts to approximately 29 listings in the May 2016 sample. Thus, this decrease is quite substantial, at around 28 percent. The decrease in entire home density after the August 2018 update is even larger with a reduction of approximately ten listings (ca. 25 percent of the 2018 sample average). Both policy changes also negatively affected the number of private rooms listed on Airbnb. However, these decreases are substantially smaller than for the number of entire homes; even though Table 2 shows that the base density of both Airbnb types are quite similar in both samples. The point estimates also suggest a small decrease in shared rooms. However, the estimates are not statistically significantly different from zero at conventional significance levels.

We next investigate the impact of the reforms on the average availability of Airbnb listings. For this purpose, we run the analyses at the Airbnb-month level. Each observation now represents one Airbnb listing in a given month. Table 5 shows regressions of the availability per 365 days on the post-dummy for all entire homes in the respective samples. The columns denoted with "Balanced" only include those Airbnb listings that are observed across the entire sample period (i.e. pre- and post-treatment).

The results confirm the results from a graphical analysis of Figure 4. The May 2016 reform results in a large drop in the mean availability of entire homes on Airbnb. However, 
the August 2018 update of the law does not. In fact, mean availability even increases for entire homes around the implementation of the update. However, Table 5 also provides some new insights. Consider the results in the columns denoted as "Balanced." These results are quite different to those using all entire homes in the sample: The reduction in availability following the May 2016 reform is lower and amounts to only five days on average. The increase following the introduction of the mandatory registration number display in August 2018 vanishes. Combined with the decrease in the number of entire homes due to both policy changes shown in Table 4 , these results suggest that the decrease in availability in May 2016 and the increase in availability in August 2018 are largely driven by the listings that exit the platform due to the policy changes. In particular, the results suggest that those listings that left the platform in May 2016 were, on average, more active than those remaining on the platform. However, those listings that exited Airbnb toward August 2018 were less active than those remaining on the platform. Considering the different nature of the two policy changes, these different impacts make sense: The end of the transition period in May 2016 effectively marked a ban on professional short-term renting on Airbnb. Therefore, those listings that should be most affected are those that were available for larger parts of the year and, therefore, more likely to be rented out professionally. However, in August 2018, professional short-term renting was already banned but a mandatory registration number display was introduced. This can be seen as the introduction of an additional cost for hosts who were occasionally renting out their apartments in their own absence. While technically allowed to do so, they would have to apply for a permit now to obtain a registration number. For many of these hosts, this additional cost might have been prohibitive and they preferred to delist their apartments from the platform instead.

\subsection{Main Results}

We next turn to our main results. Table 6 reports the estimates for three specifications for each of the samples. Columns (1) and (4) represent a naive regression of the rent per square meter on the number of nearby entire homes on Airbnb and other covariates. For model selection, the estimator proposed by Belloni et al. (2014) is used (denoted as "PDS OLS"). Columns (2) and (5) report the main estimates for an instrumental variable regression of rent per square meter on the number of nearby entire homes on Airbnb using the post-dummies as instruments. Columns (3) and (6) report similar instrumental variable regressions. Here, 
Table 6: Main results

\begin{tabular}{lcccccc}
\hline \hline & $(1)$ & $(2)$ & $(3)$ & $(4)$ & $(5)$ & $(6)$ \\
& 2016 & 2016 & 2016 & 2018 & 2018 & 2018 \\
& PDS OLS & Lasso IV & Lasso IV & PDS OLS & Lasso IV & $\begin{array}{c}\text { Lasso IV } \\
\text { Post X Postal }\end{array}$ \\
& & Post & Post X Postal & & Post & \\
\hline Second Stage & & & & & & $0.04^{* * *}$ \\
Entire homes (250m) & $0.022^{* * *}$ & $0.101^{* * *}$ & $0.069^{* * *}$ & $0.016^{* * *}$ & $0.04^{* * *}$ & {$[0.019 ; 0.062]$} \\
\hline First Stage & {$[0.014 ; 0.030]$} & {$[0.055 ; 0.146]$} & {$[0.035 ; 0.102]$} & {$[0.007 ; 0.026]$} & {$[0.019 ; 0.061]$} & \\
Post-dummy & & & & & $-3.26^{* * *}$ & $-3.318^{* * *}$ \\
& & $-2.788^{* * *}$ & $-2.906^{* * *}$ & & {$[-4.327 ;-2.194]$} & {$[-4.390 ;-2.247]$} \\
\hline N & 19,657 & 19,657 & 19,657 & 21,319 & 21,319 & 21,319 \\
Rent/m & 9.260 & 9.260 & 9.260 & 10.86 & 10.86 & 10.86 \\
Selected Xs & 107 & 116 & 108 & 83 & 95 & 93 \\
\hline \hline
\end{tabular}

Notes: Rental-month level analyses. Regressions potentially include apartment characteristics, neighborhood characteristics, a quadratic time trend, and postal code fixed effects. The estimation is done using the Belloni et al. (2014) estimator for columns (1) and (4) and using the Chernozhukov et al. 2015) estimator in the remaining columns. The square brackets show 95 percent confidence intervals. * **, *** indicate five, one, 0.1 percent significance.

however, we interact the post-dummy with postal code fixed effects in the first stage to allow for more heterogeneity. Columns (2), (3), (5), and (6) are all estimated using the Chernozhukov et al. (2015) estimator (denoted as "Lasso IV").

The lower panel of Table 6 shows the first-stage results of the IV specifications. For columns (3) and (6), we only show the estimate for the base postal code to economize on space. The results confirm that even on this disaggregated level, the impact of the reforms on the number of Airbnb listings can be seen and is significant both economically as well as statistically. Both reforms reduced the number of entire homes on Airbnb within 250 meters by approximately three units. At averages of ten and 14 units in the two samples (see Table 1), this decrease is sizeable also in relative terms.

The upper panel of Table 6 reports the main estimates of the corresponding second-stage regressions (or of the main regression in the case of the naive specifications shown in columns (1) and (4)). The results show that additional nearby entire homes on Airbnb increase rents on average. In general, accounting for potential endogeneity using instrumental variables results in larger point estimates, in line with our discussion in Section 4.1. Column (2) shows that an additional nearby entire home on Airbnb increases the average asked rent per square 
meter by approximately ten cents. The estimates using the August 2018 sample are generally lower, suggesting a smaller link between Airbnb and rents. However, the results shown in Table 5 suggest that the August 2018 policy change might mostly have affected listings on Airbnb that are unlikely to be relisted as rentals. The results in Table 6 do not take into account the availability of nearby Airbnb listings ${ }^{12}$

Table 7 reports the same specifications as Table 6 but with one difference: Rather than counting all nearby entire homes on Airbnb, we only count those nearby entire homes that are available for more than 180 out of 365 days. Table 1 shows that these listings make up approximately 36 percent of entire homes in the May 2016 sample and only 21 percent in the August 2018 sample.

The lower panel of Table 7 shows that the May 2016 reform indeed decreased the number of high availability apartments on Airbnb substantially. It furthers confirms that the August 2018 reform did not have a clear effect on high availability Airbnb apartments. For the second-stage results reported in the upper panel of Table 7, these first-stage results suggest that the August 2018 reform estimates need to be interpreted with care as the instruments seem to be weak.

The second-stage estimates suggest that the effect of an additional high availability entire home nearby is larger than the effect ignoring Airbnb availability. Column (2) now suggests a marginal effect of 13 cents per square meter per Airbnb listing. Interestingly, the point estimates using the August 2018 sample are now closer to those using the May 2016 sample, albeit noisier. This result is in line with the first-stage regressions showing that the instrument is weak for high availability apartments in August. That the point estimates are closer to those using the May 2016 sample indicates, however, that counting only the highly active nearby Airbnb listings might be a more relevant measure for the question at hand.

This intuition could also explain the differences in coefficients between the two treatment dates in Table 6. In these results, the average decrease in nearby entire homes due to the policy change together with the decrease in average rents in the sample effectively identify the estimate. In the August 2018 sample, however, a large decrease in entire homes did not result in a corresponding decrease in average asked rents. That is why the point estimates

\footnotetext{
${ }^{12}$ If we include all available covariates and conduct a regular OLS/IV analysis, the point estimates for the May 2016 sample are still positive but smaller and significant only at lower confidence levels. For the August 2018 sample, using all covariates results in statistically insignificant and negative point estimates for the IV methods.
} 
Table 7: Main results using high availability Airbnb listings only

\begin{tabular}{|c|c|c|c|c|c|c|}
\hline & $(1)$ & (2) & (3) & (4) & (5) & (6) \\
\hline & 2016 & 2016 & 2016 & 2018 & 2018 & 2018 \\
\hline & PDS OLS & Lasso IV & Lasso IV & PDS OLS & Lasso IV & Lasso IV \\
\hline & & Post & Post X Postal & & Post & Post X Postal \\
\hline \multicolumn{7}{|l|}{ Second Stage } \\
\hline Entire homes, & $0.04^{* * *}$ & $0.132^{* * *}$ & 0.095 & $0.05^{* * *}$ & $0.118^{*}$ & $0.116^{*}$ \\
\hline available $>180$ days $(250 \mathrm{~m})$ & {$[0.021 ; 0.058]$} & {$[0.061 ; 0.202]$} & {$[-0.009 ; 0.199]$} & {$[0.023 ; 0.077]$} & {$[0.024 ; 0.211]$} & {$[0.023 ; 0.209]$} \\
\hline \multicolumn{7}{|l|}{ First Stage } \\
\hline \multirow[t]{2}{*}{ Post-dummy } & & $-1.529^{* * *}$ & $-1.531^{* * *}$ & & 0.048 & $-0.224^{* *}$ \\
\hline & & {$[-1.963 ;-1.095]$} & {$[-1.967 ;-1.095]$} & & {$[-0.166 ; 0.262]$} & {$[-0.378 ;-0.070]$} \\
\hline N & 19,657 & 19,657 & 19,657 & 21,319 & 21,319 & 21,319 \\
\hline $\operatorname{Rent} / m^{2}$ & 9.260 & 9.260 & 9.260 & 10.86 & 10.86 & 10.86 \\
\hline Selected Xs & 77 & 76 & 72 & 91 & 100 & 101 \\
\hline
\end{tabular}

Notes: Rental-month level analyses. The Airbnb counts include only those nearby entire homes that are available for more than 180 out of 365 days. All other estimation details are equivalent to those reported in Table 6. The square brackets show 95 percent confidence intervals. $*, * *, * * *$ indicate five, one, 0.1 percent significance.

are lower than in the May 2016 sample. The results in Table 7 now actually suggest that this difference is because in Table 6 we used a less relevant measure for nearby Airbnb density. If we instead only count those nearby entire homes that are available for less than 180 days a year, the results suggest smaller effects than those reported in Table 6. We report these results in Appendix A.2.

\section{Robustness}

In this section, we present some additional results to address concerns about our identification and check the robustness of our results. First, we address the concern that seasonality might be driving our results. Second, we show how our results react to the use of different Airbnb circle sizes. Third, we discuss how our results change if we focus the analysis on the city center.

\subsection{Seasonality}

Because we focus on seven-month windows around the policy changes in our main analyses, we cannot include month fixed effects to take into account seasonality. Therefore, we propose two approaches to discuss the role seasonality plays in our results. First, we run placebo 
specifications for the first-stage regression to understand if the decrease in Airbnb listings that we assign to the treatments might be due to seasonality. Second, we conduct an analysis in which we first deseasonalize both the rent per square meter as well as the count of nearby entire homes on Airbnb by regressing both on a constant and month fixed effects. We then use the residuals of these regressions and implement the main analyses as reported in Table 6 .

For the placebo specifications, which can also be viewed as empirical assessments of our identification strategy, we artificially shift the treatment month and use a seven-month window around the artificial treatment month for the analysis. For each of these placebo treatment samples, we run the same analysis as in columns (2) and (5) of Table 6 and investigate the first-stage results. Figure 9 reports the coefficient estimates for the postdummy for each of these artificial treatment samples. The y-axis shows the point estimates and the $\mathrm{x}$-axis shows the corresponding placebo treatment months. Because of the gaps in the Airbnb data, we cannot conduct the analysis for all months for which we have rent data. More specifically, we only include those treatment months for which we have at least two months of Airbnb data prior to and two months after the treatment.

The results show that the drop in Airbnb numbers after May 2016 and August 2018 clearly stem from the policy changes, as none of the other coefficients are equivalent in absolute size. Toward the end of the transition period in May 2016, there seems to be some anticipation, with the drop actually already starting in February 2016. If we use February 2016 as the treatment month, the estimated effects in the second stage are similar (see Appendix A.3).

These results also indicate that it is difficult to interpret the second-stage results from such a placebo exercise. Figure 9 shows that the post-dummy is a weak instrument for many of the placebo treatment months away from the actual policy months. Consequently, it is not clear that the corresponding second-stage estimates would be unbiased. Therefore, we propose a different method to assess the impact of seasonality on our second-stage results instead. We deseasonalize rent per square meter as well as the number of nearby entire homes on Airbnb by regressing both on month fixed effects and a constant. We then use the residuals from these regressions in our main specifications. To account for the additional variation from the deseasonalization preceding the main analysis, we use the bootstrap for inference. For more details on our bootstrapping procedure, please refer to Appendix A.4.

Table 8 reports the results of this exercise. The results show that seasonality does not seem to drive our results in the May 2016 sample. The results using IV for the August 2018 


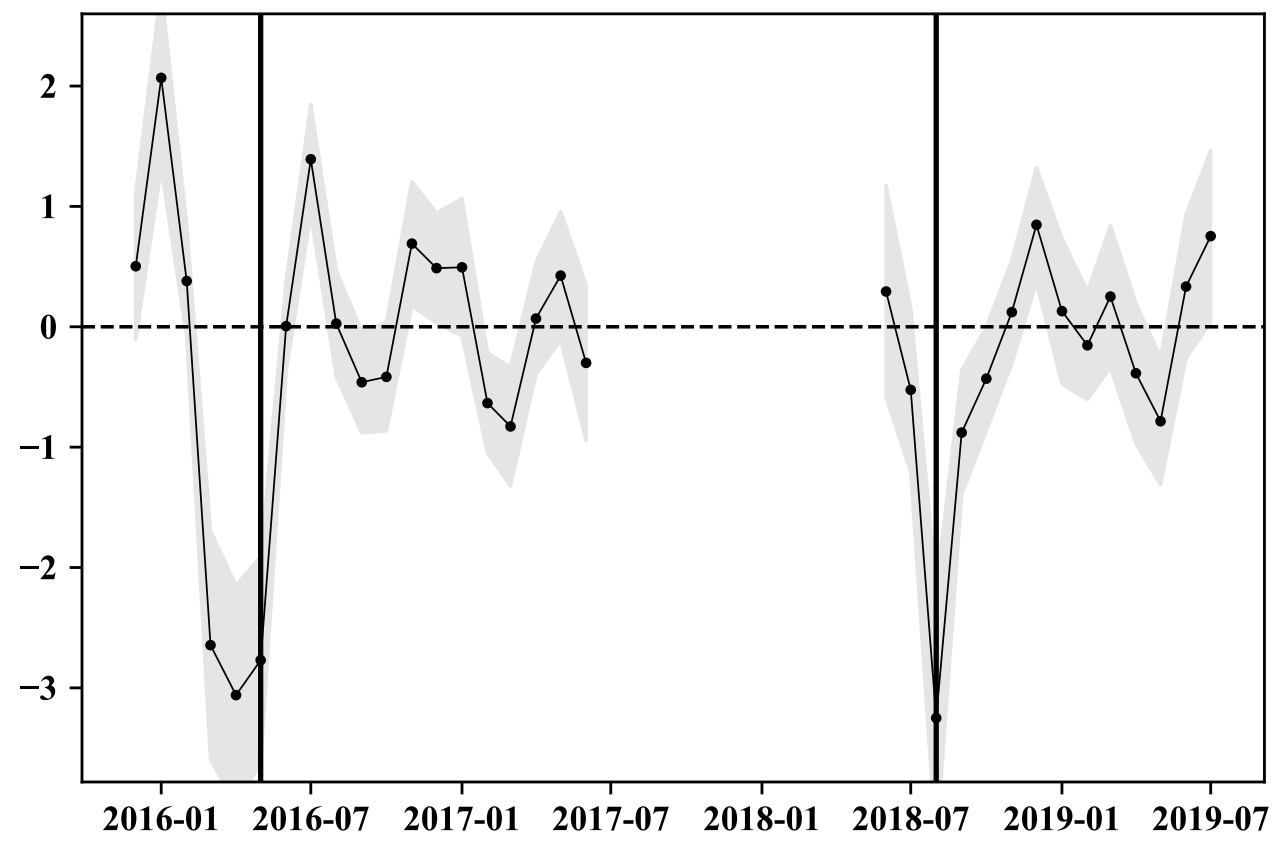

Figure 9: First-stage regressions of a Lasso IV of rent per $m^{2}$ on entire homes on Airbnb (250m) using a shifting post-dummy as an instrument. The samples always consist of the six months surrounding the treatment month and the treatment month. The plot shows the coefficient estimates on the $\mathrm{y}$-axis and the posited treatment month on the $\mathrm{x}$-axis. The shaded areas show 95 percent confidence intervals. 
Table 8: Main results using deseasonalized variables

\begin{tabular}{lcccccc}
\hline \hline & $(1)$ & $(2)$ & $(3)$ & $(4)$ & $(5)$ & $(6)$ \\
& 2016 & 2016 & 2016 & 2018 & 2018 & 2018 \\
& PDS OLS & Lasso IV & Lasso IV & PDS OLS & $\begin{array}{c}\text { Lasso IV } \\
\text { Lasso IV }\end{array}$ & $\begin{array}{c}\text { Post } \\
\text { Post X Postal }\end{array}$ \\
\hline Entire homes (250m) & $\begin{array}{c}0.018^{* * *} \\
{[0.011 ; 0.024]}\end{array}$ & $\begin{array}{c}0.108^{* * *} \\
{[0.065 ; 0.153]}\end{array}$ & $\begin{array}{c}0.046^{* * *} \\
{[0.023 ; 0.067]}\end{array}$ & $0.012^{* * *}$ & 0.007 & -0.002 \\
\hline Draws & 1000 & 1000 & 1000 & 1000 & 1000 & {$[-0.016 ; 0.014]$} \\
\hline \hline
\end{tabular}

Notes: Rental-month level analyses. We deseasonalize the rent per square meter and the number of nearby entire homes on Airbnb by regressing them on month fixed effects and a constant first. We then use the resulting residuals in the estimations. All other estimation details are equivalent to those reported in Table 6. For inference, we draw bootstrap samples before conducting the deseasonalization and estimation. The square brackets show 95 percent confidence intervals calculated as the 2.5 and 97.5 sample percentiles of the bootstrapped coefficient estimates. * **, *** indicate five, one, 0.1 percent significance, calculated using the percentile bootstrap. For more details on our bootstrapping procedure, please refer to Appendix A.4.

sample are no longer statistically significantly different from zero. This could again be a result of the fact that the August 2018 reform did not affect highly active Airbnb listings as much as the May 2016 reform.

\subsection{Airbnb Circle Size}

The choice to use a distance of 250 meters to count the number of Airbnb listings nearby a rental is ad-hoc. Choosing the size of the circle to draw around each rental is subject to a trade-off. On the one hand, we expect Airbnb listings that are closer to a rental to have a larger impact on rents on average. Choosing a larger circle size would therefore dilute the estimated effects. On the other hand, the location of Airbnb listings is anonymized by the platform and randomly shifted by up to 150 meters. Choosing a smaller circle size makes the measurement error resulting from this anonymization more severe. Our main results use circles with a radius of 250 meters. In the following, we report the same estimations, but using circle sizes with radii of 500 and 1000 meters.

Table 9 shows that larger circle sizes result in smaller effect sizes. This is in line with our intuition that closer Airbnb listings should have a larger impact on rents. At the same time, the confidence intervals become tighter with larger circle sizes, which is in line with the idea that larger circle sizes allow more precise Airbnb counts as the measurement error introduced 
Table 9: Main results using different circle sizes

\begin{tabular}{|c|c|c|c|c|c|c|}
\hline & (1) & $(2)$ & (3) & (4) & $(5)$ & (6) \\
\hline & 2016 & 2016 & 2016 & 2018 & 2018 & 2018 \\
\hline & PDS OLS & Lasso IV & Lasso IV & PDS OLS & Lasso IV & Lasso IV \\
\hline & & Post & Post X Postal & & Post & Post X Postal \\
\hline \multirow[t]{2}{*}{ Entire homes (500m) } & $0.004^{*}$ & $0.038^{* * *}$ & $0.025^{* * *}$ & $0.004^{*}$ & 0.007 & 0.006 \\
\hline & {$[0.000 ; 0.007]$} & {$[0.024 ; 0.053]$} & {$[0.013 ; 0.036]$} & {$[0.000 ; 0.008]$} & {$[-0.001 ; 0.015]$} & {$[-0.001 ; 0.013]$} \\
\hline Selected Xs & 115 & 107 & 106 & 61 & 70 & 61 \\
\hline \multirow[t]{2}{*}{ Entire homes $(1000 \mathrm{~m})$} & 0.0 & $0.008^{* * *}$ & $0.007^{* * *}$ & 0.001 & 0.002 & 0.002 \\
\hline & {$[-0.001 ; 0.002]$} & {$[0.004 ; 0.012]$} & {$[0.003 ; 0.010]$} & {$[-0.001 ; 0.002]$} & {$[-0.000 ; 0.004]$} & {$[-0.000 ; 0.004]$} \\
\hline Selected Xs & 103 & 96 & 102 & 41 & 94 & 94 \\
\hline $\mathrm{N}$ & 19,657 & 19,657 & 19,657 & 21,319 & 21,319 & 21,319 \\
\hline $\operatorname{Rent} / m^{2}$ & 9.260 & 9.260 & 9.260 & 10.86 & 10.86 & 10.86 \\
\hline
\end{tabular}

Notes: Rental-month level analyses. We use the number of nearby entire homes on Airbnb within 500 meters and 1000 meters as our Airbnb measure. All other estimation details are equivalent to those reported in Table 6 . The square brackets show 95 percent confidence intervals. *, **, *** indicate five, one, 0.1 percent significance.

due to the anonymization of the exact location becomes less severe. In all specifications, however, the effect of Airbnb on rents is positive, although the exact point estimates do vary.

\subsection{City Center versus the Entire City}

Figure $7 \mathrm{~b}$ shows that most Airbnb listings are located within the city center. This fact might lead to concerns that very little variation in the number of Airbnb listings might be driving our results if we include districts in which the number of Airbnb listings does not change (much) over time. The upper panel of Table 10 therefore shows the results of conducting the main analysis for only those listings within the city center. We define the city center as all areas that are within the so-called "S-Bahnring," a circular train track that surrounds the inner city. The point estimates are indeed smaller but still clearly positive and significant for the May 2016 sample. The estimates for the August 2018 sample are no longer significant. This pattern might again be a result of high-availability Airbnb listings having a larger impact on rents.

If we focus on only those entire homes that are available for more than 180 days per year, the point estimates for the May sample are again larger. We report the results in the lower panel of Table 10. However, the point estimates in the August 2018 are still not statistically 
Table 10: Main results for the city center

\begin{tabular}{|c|c|c|c|c|c|c|}
\hline & (1) & (2) & (3) & (4) & (5) & (6) \\
\hline & 2016 & 2016 & 2016 & 2018 & 2018 & 2018 \\
\hline & PDS OLS & Lasso IV & Lasso IV & PDS OLS & Lasso IV & Lasso IV \\
\hline & & Post & Post X Postal & & Post & Post X Posta \\
\hline \multirow[t]{2}{*}{ Entire homes on Airbnb (250m) } & $0.013^{* *}$ & $0.046^{* *}$ & $0.032^{*}$ & 0.006 & 0.02 & 0.015 \\
\hline & {$[0.005 ; 0.021]$} & {$[0.011 ; 0.081]$} & {$[0.001 ; 0.064]$} & {$[-0.003 ; 0.015]$} & {$[-0.012 ; 0.052]$} & {$[-0.017 ; 0.048$} \\
\hline Selected Xs & 27 & 33 & 29 & 35 & 37 & 36 \\
\hline \multirow[t]{2}{*}{ Entire homes, available $>180$ days $(250 \mathrm{~m})$} & $0.023^{* *}$ & $0.068^{*}$ & $0.061^{*}$ & 0.022 & 0.022 & 0.042 \\
\hline & {$[0.006 ; 0.040]$} & {$[0.016 ; 0.120]$} & {$[0.002 ; 0.121]$} & {$[-0.002 ; 0.046]$} & {$[-0.131 ; 0.176]$} & {$[-0.099 ; 0.184$} \\
\hline Selected Xs & 26 & 31 & 28 & 25 & 36 & 33 \\
\hline $\operatorname{Rent} / m^{2}$ & 10.78 & 10.78 & 10.78 & 12.88 & 12.88 & 12.88 \\
\hline Selected Xs & 26 & 31 & 28 & 25 & 36 & 33 \\
\hline
\end{tabular}

Notes: Rental-month level analyses. We use only those listings located in the city center (defined as the area within the S-Bahnring). All other estimation details are equivalent to those reported in Table6. The square brackets show 95 percent confidence intervals. *, **, *** indicate five, one, 0.1 percent significance.

significantly different from zero, although they are positive. This non-significance most likely is a result of the August 2018 reform not causing sufficient variation in the availability of Airbnb listings. Combined with the reduced sample size due to restricting the analysis on the city center, we can no longer identify an effect in the August 2018 sample.

\section{Heterogeneity}

Thus far, we have only considered average effects. However, the effect of Airbnb on rents is most likely heterogeneous across different regions and apartments. Therefore, we next investigate effect heterogeneity across different regions of the city as well as different types of rentals.

\subsection{Geographic Heterogeneity}

We first turn to a look at the heterogeneous effects of Airbnb on rents across the city. To do so, we stratify the sample by district and conduct the same analysis as reported in column (2) in Table 6 using the May 2016 sample for each of the sub-samples. To first understand the heterogeneity of the effect of the May 2016 reform, Figure 10a shows the first-stage estimates of the post-dummy coefficient for each district. Unsurprisingly, the central districts that had a higher density of Airbnb listings pre-reform (see Figure 7b) also experience the 
largest decreases in entire homes due to the law. For every district, the point estimates are negative. However, note that not all of the point estimates are actually statistically significantly different from zero. Districts for which the point estimates are not statistically significantly different from zero at the 95 percent confidence level are overlaid with diagonal stripes. Additionally, ${ }^{*}, * *, * * *$ indicate five, one, 0.1 percent significance in the legend.

Figure $10 \mathrm{~b}$ shows the second-stage estimates of the effect of Airbnb on rents corresponding to the first-stage results presented in Figure10a, Note that this figure suggests negative effects for three districts. However, the estimates are not statistically significant at conventional confidence levels for any of these districts. All of the statistically significant estimates suggest a positive effect of Airbnb on rents. Further, the estimates suggest effect heterogeneity across districts with increases in rent per square meter ranging from eight to 46 cents per additional nearby entire home.

Against our intuition, these estimates suggest that the marginal effect of additional Airbnb listings is larger in the outskirts of the city. In fact, plotting the estimates that are statistically significant at the 95 percent confidence level against the district-level mean number of entire homes listed on Airbnb in a 250 meter circle shows that districts with a lower Airbnb density tend to be subject to larger marginal Airbnb effects. This result is shown in Figure 11 . Although the line is not monotonically decreasing, it does suggest decreasing marginal effects of Airbnb on rents. One possible explanation for this pattern might be that with high Airbnb density, the negative externalities on residents (e.g. noise at night) might become large enough to reduce residential demand in the area. Exploring these channels would be interesting but is outside the scope of this paper. These results are not conclusive of course. First, the estimates are noisy and the insight is based on the results for seven districts only. Second, the difference in mean Airbnb density is based on different districts here. There might be some district-level characteristics that drive both Airbnb density and the marginal effect of Airbnb on rents. Nevertheless, these results are novel to the literature and give future research a direction to explore further in more suitable settings.

Note that Figure 10a suggests that more central districts experienced larger decreases in the number of entire homes listed on Airbnb as a result of the May 2016 reform. At the same time, however, Figure $10 \mathrm{~b}$ suggests that these same districts are subject to lower marginal effects of Airbnb on rents. When considering how the May 2016 reform may have impacted rents across different districts, these two effects imply opposite relationships between more 

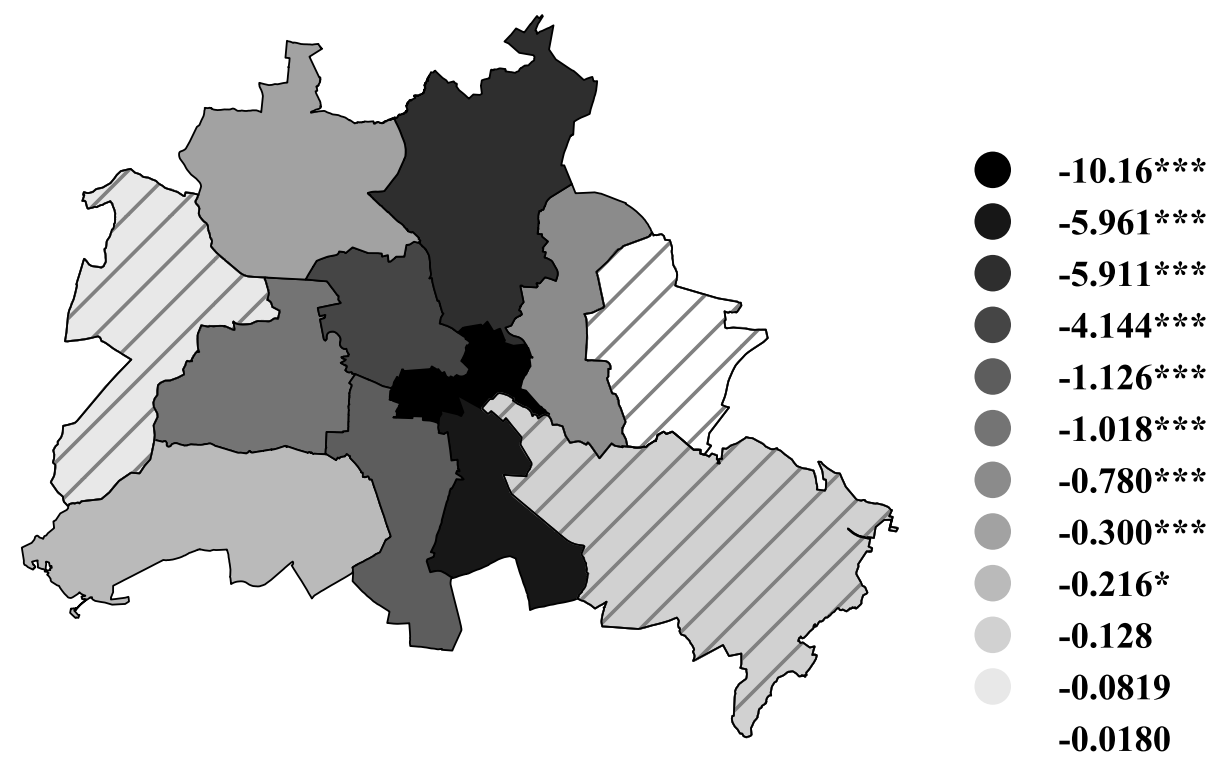

(a) First-stage estimates for the post-dummy
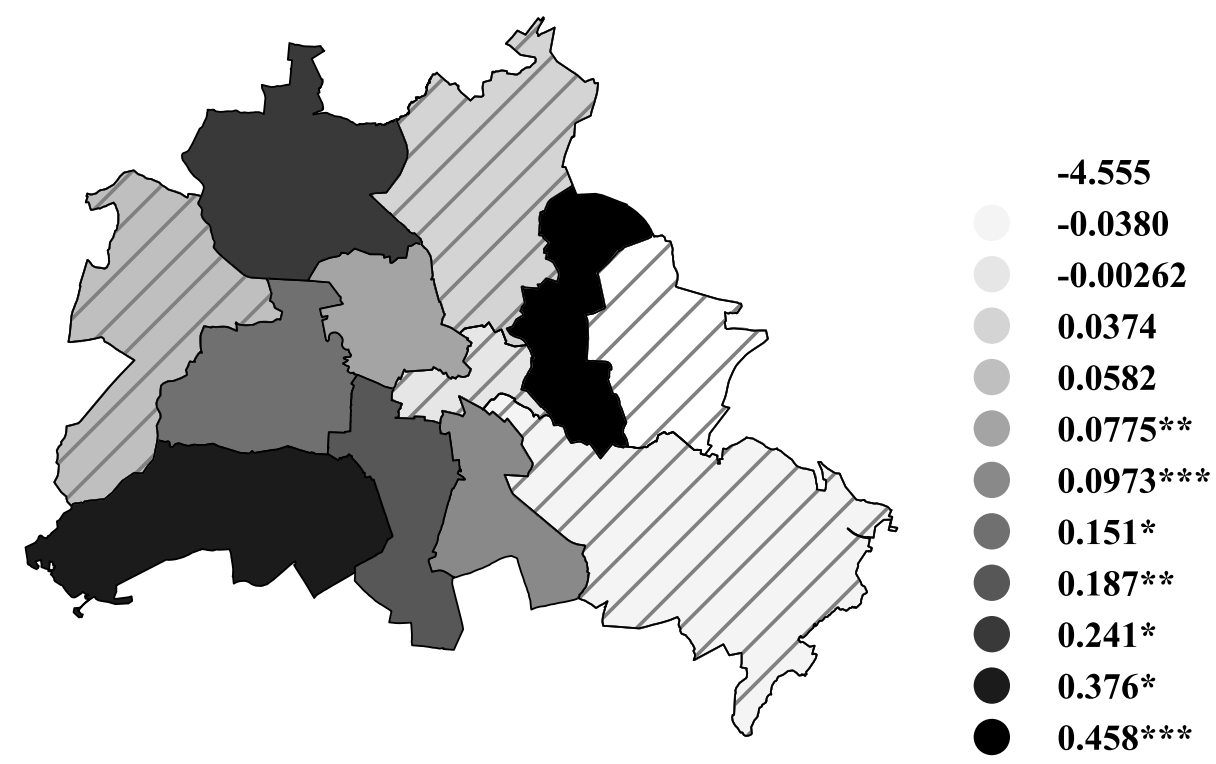

(b) Second-stage estimates of the Airbnb effect

Figure 10: District-stratified Lasso IV regressions of rent per square meter on the number of entire homes on Airbnb (250m) using the post-dummy as an instrument for the May 2016 sample. The specification is identical to the one reported in column (2) of Table 6. *, $* *, * * *$ indicate five, one, 0.1 percent significance. Districts for which the coefficient is not statistically significant at the 95 percent confidence level are marked with diagonal stripes. 


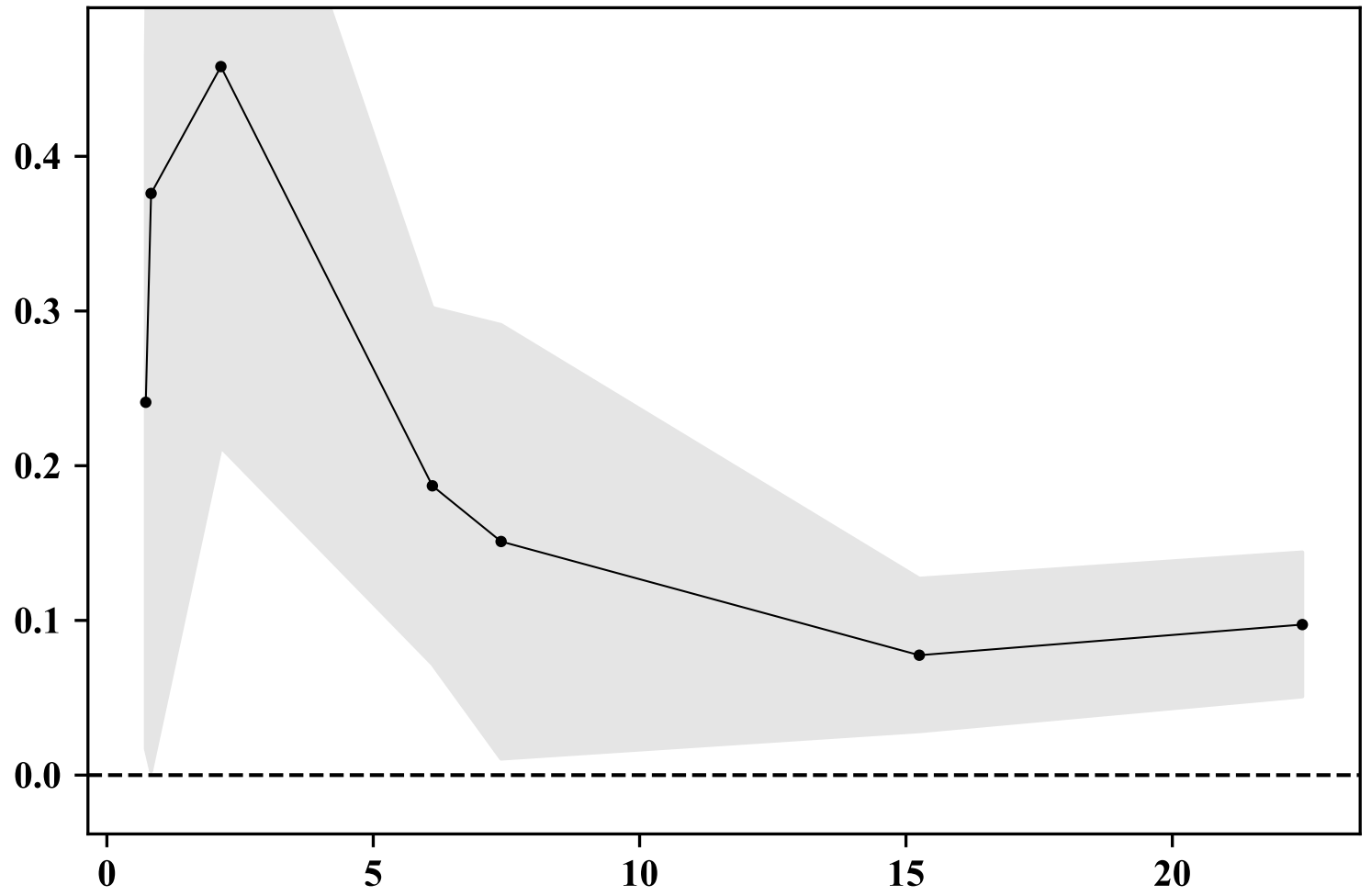

Figure 11: Estimates by Airbnb distribution: Statistically significant estimates (95 percent confidence level) from Figure 10b plotted against the mean number of entire homes on Airbnb (250m) by district. Shaded area shows 95 percent confidence intervals. 
central and outer districts: On the one hand, the decrease in the number of Airbnb listings was larger in the city center, on the other hand, the marginal effect of each of these Airbnb listings on rents is lower. To give an idea about what our estimates imply for the cumulative effect of the May 2016 reform on rents, we multiply the estimates shown in Figures 10a and 10b, Further, we calculate the average size of rentals for each district and multiply it with the product of the two stages. The result can be interpreted as the monthly rent that an average apartment in each district saved due to the May 2016 reform. The results of this exercise are shown in Figure 12a. The results suggest that the effect of the law on rents is heterogeneous across districts and amounts to up to approximately 38 Euros per month in the more popular Airbnb districts. Figure $12 \mathrm{~b}$ shows the results of Figure $12 \mathrm{a}$ as a percentage of the average rent calculated by district. The cumulative effect of the law is calculated to decrease total monthly rent up to six percent.

\subsection{Heterogeneity by Apartment Type}

We next turn to an investigation of the heterogeneity of the Airbnb effect by different types of apartments. In particular, we are interested in whether rentals with a different number of rooms are affected differently by nearby Airbnb listings. For this purpose, we split the sample of rentals by the number of bedrooms. Note that most apartments have integer number of bedrooms, but sometimes apartments also have, for example, half rooms. In these cases, we round down. For example, we group all one-bedroom apartments together with all one-and-a-half-bedroom apartments. Further, we combine all apartments with four or more bedrooms in one group. For these sub-samples, we then conduct the same analysis as in Table 6. Table 11 reports the results of this exercise.

The results suggest some effect heterogeneity. In particular, column (3) suggests somewhat larger effects for apartments with more bedrooms. In general, however, the results do not suggest a clear-cut pattern of heterogeneity across apartments with different numbers of bedrooms.

\section{Conclusion}

The impact of short-term rental platforms such as Airbnb on the long-term rental market is a politically relevant and much discussed topic. Even though cities around the world have already introduced policies to regulate short-term rental platforms, empirical evidence 

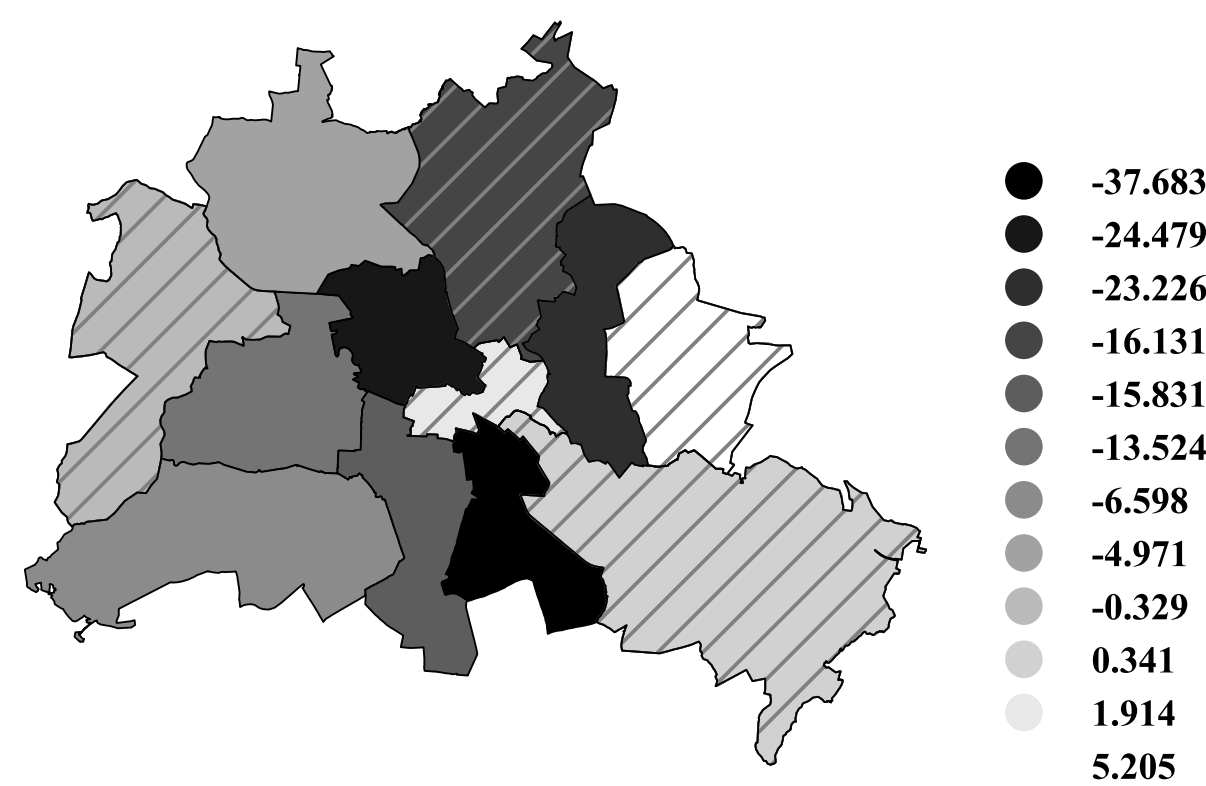

(a) Implied cumulative decrease in monthly rents

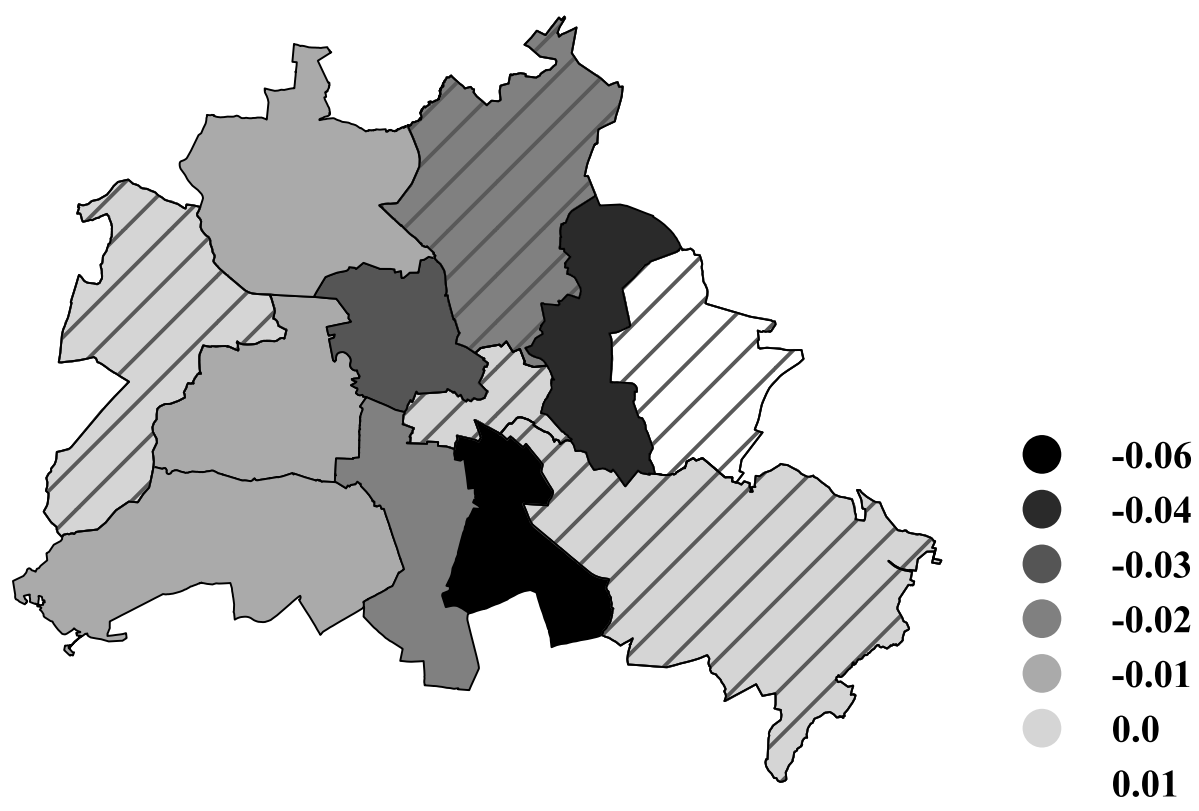

(b) Implied cumulative decrease in monthly rents relative to average rent

Figure 12: Cumulative decrease in monthly rents. Products of the estimates from Figure 10a. Figure 10b, as well as the average apartment size (Figure 12a) and relative to average monthly rent by district (Figure 12b). Districts for which the second-stage coefficient is not statistically significant at the 95 percent confidence level are marked with diagonal stripes (these districts include all districts for which the first-stage coefficient is not statistically significant at the 95 percent confidence level). 
Table 11: Main results stratified by number of bedrooms

\begin{tabular}{|c|c|c|c|c|c|c|}
\hline & (1) & $(2)$ & $(3)$ & $(4)$ & $(5)$ & (6) \\
\hline & 2016 & 2016 & 2016 & 2018 & 2018 & 2018 \\
\hline & PDS OLS & Lasso IV & Lasso IV & PDS OLS & Lasso IV & Lasso IV \\
\hline & & Post & Post X Postal & & Post & Post X Postal \\
\hline \multicolumn{7}{|l|}{$0 \leq$ Bedrooms $<2$} \\
\hline \multirow[t]{2}{*}{ Entire homes $(250 \mathrm{~m})$} & $0.025^{* * *}$ & 0.073 & 0.069 & $0.018^{*}$ & 0.012 & 0.011 \\
\hline & {$[0.012 ; 0.038]$} & {$[-0.002 ; 0.149]$} & {$[-0.006 ; 0.145]$} & {$[0.002 ; 0.033]$} & {$[-0.073 ; 0.098]$} & {$[-0.074 ; 0.096]$} \\
\hline $\mathrm{N}$ & 3,422 & 3,422 & 3,422 & 4,010 & 4,010 & 4,010 \\
\hline $\operatorname{Rent} / m^{2}$ & 9.800 & 9.800 & 9.800 & 11.44 & 11.44 & 11.44 \\
\hline Selected Xs & 30 & 32 & 32 & 37 & 28 & 26 \\
\hline \multicolumn{7}{|l|}{$2 \leq$ Bedrooms $<3$} \\
\hline \multirow[t]{2}{*}{ Entire homes $(250 \mathrm{~m})$} & $0.014^{* *}$ & $0.056^{* * *}$ & $0.061^{* * *}$ & $0.02^{* * *}$ & $0.042^{* *}$ & $0.04^{* *}$ \\
\hline & {$[0.005 ; 0.023]$} & {$[0.024 ; 0.088]$} & {$[0.034 ; 0.089]$} & {$[0.009 ; 0.030]$} & {$[0.016 ; 0.068]$} & {$[0.015 ; 0.065]$} \\
\hline $\mathrm{N}$ & 8,855 & 8,855 & 8,855 & 9,622 & 9,622 & 9,622 \\
\hline $\operatorname{Rent} / m^{2}$ & 9.120 & 9.120 & 9.120 & 10.70 & 10.70 & 10.70 \\
\hline Selected Xs & 116 & 116 & 110 & 53 & 76 & 65 \\
\hline \multicolumn{7}{|l|}{$3 \leq$ Bedrooms $<4$} \\
\hline \multirow[t]{2}{*}{ Entire homes $(250 \mathrm{~m})$} & $0.026^{* *}$ & $0.096^{*}$ & $0.072^{* *}$ & $0.025^{* * *}$ & 0.031 & $0.036^{*}$ \\
\hline & {$[0.010 ; 0.042]$} & {$[0.023 ; 0.168]$} & {$[0.021 ; 0.123]$} & {$[0.014 ; 0.035]$} & {$[-0.044 ; 0.106]$} & {$[0.001 ; 0.071]$} \\
\hline $\mathrm{N}$ & 5,258 & 5,258 & 5,258 & 5,545 & 5,545 & 5,545 \\
\hline $\operatorname{Rent} / m^{2}$ & 9.010 & 9.010 & 9.010 & 10.55 & 10.55 & 10.55 \\
\hline Selected Xs & 59 & 49 & 56 & 41 & 41 & 44 \\
\hline \multicolumn{7}{|l|}{ Bedrooms $\geq 4$} \\
\hline \multirow[t]{2}{*}{ Entire homes $(250 \mathrm{~m})$} & $0.03^{* *}$ & $0.067^{*}$ & $0.112^{* *}$ & 0.016 & $0.066^{*}$ & $0.085^{* *}$ \\
\hline & {$[0.009 ; 0.050]$} & {$[0.006 ; 0.128]$} & {$[0.029 ; 0.195]$} & {$[-0.001 ; 0.033]$} & {$[0.004 ; 0.127]$} & {$[0.022 ; 0.147]$} \\
\hline $\mathrm{N}$ & 2,122 & 2,122 & 2,122 & 2,142 & 2,142 & 2,142 \\
\hline $\operatorname{Rent} / m^{2}$ & 9.590 & 9.590 & 9.590 & 11.32 & 11.32 & 11.32 \\
\hline Selected Xs & 44 & 61 & 54 & 17 & 45 & 40 \\
\hline
\end{tabular}

Notes: Analysis as in Table 6, but with rentals stratified by the number of bedrooms. The square brackets show 95 percent confidence intervals. *, **,*** indicate five, one, 0.1 percent significance. 
studying the causal link between the spread of Airbnb and outcomes in the housing market only started emerging in 2017. Establishing and quantifying the causal impact of Airbnb on rents is challenging.

We contribute to this literature by providing the first causal study on this topic for Berlin, Germany. We further contribute to the small group of papers that use a policy change as a natural experiment to address the inherent endogeneity in a causal analysis of Airbnb and rents. We use legislation that was passed by the City of Berlin ( $\mathrm{ZwVbG}$ ) to curb the mis-use of apartments as full-time short-term rentals. For the analysis, we combine data on asked rents, Airbnb in Berlin, and neighborhood characteristics from various data sources. To account for observable confounders, we use a rich set of potential regressors that explain both the number of nearby Airbnb listings as well as the rents of specific apartments. We select the relevant regressors using the so-called double-Lasso estimators proposed by Belloni et al. (2014) and Chernozhukov et al. (2015) in order to remain agnostic in the model selection process.

In a first step, we find that the policy changes resulted in marked decreases in the number of Airbnb listings in Berlin. Furthermore, in particular when the law first fully took effect in May 2016, not only did the number of Airbnb listings (particularly entire homes listed on Airbnb) decrease, but the average number of days per year that an Airbnb listing was available for booking also dropped substantially. This change in availability was different when the law was updated in August 2018. While this update also resulted in a strong decrease in the number of entire homes listed on Airbnb in Berlin, it mostly affected less active listings.

Our results suggest that one additional entire home listed on Airbnb within 250 meters of a rental apartment increases the average asked monthly rent per square meter by at least seven cents. Focusing on highly active Airbnb listings, the estimated impact is even larger at 13 cents per additional Airbnb. We find that this effect is heterogeneous across districts. We document suggestive evidence that the effect might be larger in districts with a lower Airbnb density.

Thus, our paper confirms the results of previous research that finds that rents increase with increasing Airbnb popularity in the US (Horn and Merante, 2017, Koster et al., 2018, Barron et al., 2020) and in Europe (Garcia-López et al., 2019). However, our results also document some new results with regard to the heterogeneity of the effect. In particular, we 
find that the more highly available Airbnb listings are those that seem to be most relevant for the rental market.

For policy-makers, these results suggest that regulation of the short-term market aiming to ease the burden on the long-term rental market should take into account carefully which types of short-term rental listings will be affected. While the initial introduction of the regulation in Berlin strongly reduced the number of high availability listings in Berlin, its update mostly affected less active listings. With regard to rents, the initial introduction (or, rather, the end of the transition period after the law was introduced) was then most likely more effective in relieving the rental market. The August 2018 update, however, affected less active Airbnb listings more and, thusly, might have hurt hosts who profit from occasionally hosting on Airbnb but did not, in fact, withdraw apartments from the long-term rental market. These nuances are new to the literature and should be explored more by future research to further inform the policy debate. 


\section{References}

Barron, K., Kung, E., and Proserpio, D. (2020). The Effect of Home-Sharing on House Prices and Rents: Evidence from Airbnb. Marketing Science, forthcoming.

Belloni, A., Chernozhukov, V., and Hansen, C. (2014). Inference on Treatment Effects after Selection among High-Dimensional Controls. The Review of Economic Studies, 81(2):608650.

Chernozhukov, V., Hansen, C., and Spindler, M. (2015). Post-Selection and PostRegularization Inference in Linear Models with Many Controls and Instruments. American Economic Review: Papers \& Proceedings, 105(5):486-490.

Garcia-López, M.-À., Jofre-Monseny, J., Mazza, R. M., and Segú, M. (2019). Do Shortterm Rental Platforms Affect Housing Markets? Evidence from Airbnb in Barcelona. IEB Working Paper 2019/05.

Horn, K. and Merante, M. (2017). Is home sharing driving up rents? Evidence from Airbnb in Boston. Journal of Housing Economics, 38:14-24.

Huber, K., Lindenthal, V., and Waldinger, F. (2019). Discrimination, Managers, and Firm Performance: Evidence from "Aryanizations" in Nazi Germany. Working Paper.

Koster, H., van Ommeren, J., and Volkhausen, N. (2018). Short-term rentals and the housing market: Quasi-experimental evidence from Airbnb in Los Angeles. CEPR Discussion Paper, DP13094.

Mense, A., Michelsen, C., and Kholodilin, K. A. (2017). Empirics on the causal effects of rent control in Germany. FAU Discussion Papers in Economics, 24/2017.

Valentin, M. (2020). Regulating Short-Term Rental Housing: Evidence from New Orleans. Real Estate Economics, forthcoming.

Yrigoy, I. (2019). Rent gap reloaded: Airbnb and the shift from residential to touristic rental housing in the Palma Old Quarter in Mallorca, Spain. Urban Studies, 56(13):2709-2726. 


\section{A Appendix}

\section{A.1 Our Application of Chernozhukov et al. (2015)}

We briefly outline the algorithm of the estimator applied to our problem here. For a more detailed discussion, please refer to Chernozhukov et al. (2015). Consider the moment condition

$$
E\left[\left(\tilde{\rho}_{i t}^{y}-\tilde{\rho}_{i t}^{a b b} \alpha\right) \tilde{\nu}_{i t}\right]=0,
$$

where $\tilde{\rho}_{i t}^{y}=y_{i t}-x_{i t}^{\prime} \theta, \tilde{\rho}_{i t}^{a b b}=a b b_{i t}-x_{i t}^{\prime} \vartheta$, and $\tilde{\nu}_{i t}=x_{i t}^{\prime} \delta+\gamma \mathbb{1}(t \geq l a w)-x_{i t}^{\prime} \vartheta$.

Chernozhukov et al. (2015) show that this moment condition is valid around the true parameter values, even for small deviations from the true parameter values. Because of this result, the moment condition is "immune" to small selection errors. This moment condition corresponds to an exogeneity assumption when regressing $\tilde{\rho}_{i t}^{y}$ on $\tilde{\rho}_{i t}^{a b b}$ using $\tilde{\nu}_{i t}$ as an instrument. Therefore, the authors propose to estimate exactly this instrumental variable regression in order to obtain an estimate for $\alpha$, the coefficient of interest.

Chernozhukov et al. (2015) propose to obtain the sample equivalents of the necessary expressions using the following algorithm:

1. Conduct a first-stage regression of $a b b_{i t}$ on $\mathbb{1}(t \geq l a w)$ and $x_{i t}$ and denote the corresponding coefficients as $\hat{\gamma}$ and $\hat{\delta}$. Obtain predicted Airbnb counts using $a \hat{b} b_{i t}=\hat{\gamma} \mathbb{1}(t \geq$ law) $+x_{i t}^{\prime} \hat{\delta}$.

2. Conduct a regression of $y_{i t}$ on $x_{i t}$ and denote the corresponding coefficient as $\hat{\beta}$.

3. Conduct a regression of $a \hat{b} b_{i t}$ on $x_{i t}$ and denote the corresponding coefficients as $\hat{v}$.

4. Calculate $\hat{\rho}_{i t}^{y}=y_{i t}-x_{i t}^{\prime} \hat{\beta}, \hat{\rho}_{i t}^{d}=\mathbb{1}(t \geq l a w)-x_{i t}^{\prime} \hat{v}$, and $\hat{\nu}_{i t}:=\mathbb{1}(t \geq l a w) \hat{\gamma}+x_{i t}^{\prime} \hat{\delta}-x_{i t}^{\prime} \hat{\text {. }}$. Use IV regression of $\hat{\rho}_{i t}^{y}$ on $\hat{\rho}_{i t}^{d}$ using $\hat{\nu}_{i t}$ as an instrument to obtain $\hat{\alpha}$.

The authors propose to use either Lasso or Post-Lasso (OLS using variables previously selected by Lasso) to run the three regression steps and obtain the parameter estimates. Asymptotically, the choice of the estimator makes no difference. We use Lasso for the estimation.

Chernozhukov et al. (2015) show that standard inference methods for IV regression are valid for $\hat{\alpha}$. As mentioned above, the authors show that using the IV regression of the 
transformed prediction errors in step 4 amounts to using a moment restriction that makes the estimator robust to small model selection mistakes 13

\section{A.2 Main Results for Low Availability Airbnb Listings}

Table 12: Main results using low availability Airbnb listings only

\begin{tabular}{|c|c|c|c|c|c|c|}
\hline & (1) & (2) & (3) & (4) & (5) & (6) \\
\hline & 2016 & 2016 & 2016 & 2018 & 2018 & 2018 \\
\hline & PDS OLS & Lasso IV & Lasso IV & PDS OLS & Lasso IV & Lasso IV \\
\hline & & Post & Post X Postal & & Post & Post X Postal \\
\hline \multirow[t]{2}{*}{ Entire homes, available $<180$ days $(250 \mathrm{~m})$} & $0.022^{* * *}$ & $0.066^{* * *}$ & $0.064^{* * *}$ & $0.018^{* *}$ & $0.043^{*}$ & $0.032^{* *}$ \\
\hline & {$[0.012 ; 0.033]$} & {$[0.029 ; 0.104]$} & {$[0.027 ; 0.102]$} & {$[0.006 ; 0.029]$} & {$[0.003 ; 0.082]$} & {$[0.011 ; 0.054]$} \\
\hline $\mathrm{N}$ & 19,657 & 19,657 & 19,657 & 21,319 & 21,319 & 21,319 \\
\hline $\operatorname{Rent} / m^{2}$ & 9.260 & 9.260 & 9.260 & 10.86 & 10.86 & 10.86 \\
\hline Selected Xs & 127 & 134 & 124 & 78 & 80 & 96 \\
\hline
\end{tabular}

Notes: Rental-month level analyses. The Airbnb counts include only those nearby entire homes that are available for less than 180 out of 365 days. All other estimation details are equivalent to those reported in Table 6 . The square brackets show 95 percent confidence intervals. *, **, *** indicate five, one, 0.1 percent significance.

\footnotetext{
${ }^{13}$ The authors also discuss that if perfect model selection were possible, then the transformation were not necessary. Instead, it would be valid to use the union of the $x_{i t}$ that were selected in steps 1 and 2 , together with the instrument $\mathbb{1}(t \geq$ law $)$, in a regular IV framework.
} 


\section{A.3 Main Results for February 2016 Treatment}

Table 13: Main results for February 2016 treatment

\begin{tabular}{lccc}
\hline \hline & $(1)$ & $(2)$ & $(3)$ \\
& 2016 & 2016 & 2016 \\
& PDS OLS & Lasso IV & $\begin{array}{c}\text { Lasso IV } \\
\text { Post }\end{array}$ \\
& & Post X Postal \\
\hline Entire homes $(250 \mathrm{~m})$ & $0.016^{* * *}$ & $0.098^{* *}$ & $0.112^{* * *}$ \\
& {$[0.009 ; 0.024]$} & {$[0.036 ; 0.160]$} & {$[0.069 ; 0.155]$} \\
\hline $\mathrm{N}$ & 18,687 & 18,687 & 18,687 \\
Rent $/ \mathrm{m}^{2}$ & 9.070 & 9.070 & 9.070 \\
Selected Xs & 128 & 146 & 131 \\
\hline \hline
\end{tabular}

Notes: Rental-month level analyses. Same specifications as reported in Table6, except that we use February 2016 as the treatment month. The square brackets show 95 percent confidence intervals. * ${ }^{* *}, * * *$ indicate five, one, 0.1 percent significance

\section{A.4 Bootstrapping Procedure}

For the results reported in Table 8, we draw bootstrap samples before conducting the deseasonalization to account for the variation introduced by the deseasonalization procedure. Note that although the main analysis is focused around the short time windows around the May 2016 and August 2018 reforms, we need larger time windows to be able to include month fixed effects in our deseasonalization. Therefore, for the deseasonalization, we use the entire data set of rents and Airbnb listings available to us. This implies that we are drawing bootstrap samples from a larger sample that we end up using in the main estimation in each bootstrap iteration. Let $N$ denote the total number of rentals in our data. In each bootstrap iteration $s$, we then follow the following steps:

1. Draw $N$ rentals with replacement from the full data set.

2. Use this bootstrap sample and regress

$$
y_{i t}=\alpha+\beta M o n t h F E_{t}+\epsilon_{i t},
$$


where $y_{i t}$ is either the rent per square meter or the measure of nearby Airbnb listings of rental $i$ listed in month $t$. This regression yields coefficient estimates $\hat{\alpha}$ and $\hat{\beta}$.

3. Calculate $\hat{\epsilon}_{i t}=y_{i t}-\hat{\alpha}-\hat{\beta} M o n t h F E_{t}$ for both variables.

4. Use only those rentals out of the $N$ bootstrap rentals that are within the sample time window around May 2016 or August 2018. Denote the number of corresponding rentals as $N_{s}$. Note that while $N$ is constant for all bootstrap iterations, $N_{s}$ can vary. For these $N_{s}$ rentals, we run the main specifications replacing rents per square meter and the Airbnb measure with the corresponding estimated residuals.

As point estimates, we report the results from the estimation using the original sample. Denote these point estimates as $\hat{\beta}_{0}$. For inference, for each coefficient, we save all estimates from each of the bootstrap iterations. To calculate 95 percent confidence intervals, we simply use the 2.5 and 97.5 percentiles of the sample distribution of these estimates. To calculate p-values, we shift all of these estimates by their mean to center them around zero. We then calculate the probability to obtain estimate $\hat{\beta}_{0}$ given that the true parameter distribution is the distribution of estimates centered around zero. To do so, we calculate the percentage of parameter estimates that are below $0-\left|\hat{\beta}_{0}\right|$ or above $0+\left|\hat{\beta}_{0}\right|$. 